\title{
Load bearing sandwich timber walls with plywood faces and bamboo core
}

Siavash Darzi ${ }^{1}$, Hassan Karampour ${ }^{1}$, Henri Bailleres ${ }^{2}$, Benoit P. Gilbert ${ }^{1}$, and Dilum Fernando ${ }^{3}$

${ }^{1}$ Griffith School of Engineering and Built Environment, Griffith University, Gold Coast Campus, QLD 4222, Australia

${ }^{2}$ Salisbury Research Facility, Department of Agriculture and Fisheries, Salisbury, QLD 4107, Australia

${ }^{3}$ School of Civil Engineering, The University of Queensland, St Lucia QLD 4072, Australia

\begin{abstract}
:
Novel light timber sandwich panels (referred to as BCS panels herein) are manufactured by gluing plywood faces to bamboo core rings. The panels are tested in compression and in bonding shear (between bamboo and plywood). A finite element model is developed and validated against the experimental results, and is used to capture the responses of the BCS panels under axial and combined axial and bending actions. A lognormal distribution is used to represent the mechanical properties of plywood in the finite element analyses (FEA). Moreover, effect of different core configurations, face thickness, core layers and initial imperfection shapes on the axial compressive capacity of the panels are investigated. Where possible, results are compared against theoretical predictions. Current test results show that under axial compressive action, the ultimate capacity to weight ratio of the BCS panels are up to $27.3 \%$ higher than a conventional CLT panel of the same dimension. At large slenderness ratios, the proposed BCS panels have ultimate axial capacities close to the conventional CLT panels. Under combined axial and bending loading, the BCS panels outperform a CLT panel of similar size.
\end{abstract}

\section{Keywords:}

Bamboo panel; light-weight construction; sandwich walls; cross-laminated-timber; sustainable construction; timber panel 


\section{Introduction}

Sandwich structures with high stiffness-to-weight and strength-to-weight ratios, are widely used in automotive, aerospace, marine and industrial applications. Typically, a sandwich panel is made up of two outer skins (also known as faces) which are connected using a light-weight core. The skins are normally made of steel [1,2], fibre reinforced composites [3] and sometimes reinforced concrete $[4,5]$. Common material used in the core are balsa wood [6], polymeric and metallic foams [7, 8], fibre reinforced polymer (FRP) [9] and metallic alloys [10].

Majority of studies on sandwich structures are focused on flexural behaviour under environmental exposure [11] and out-of-plane loading including static, shock, impact and blast resistance $[12,13]$. With the advancement of fabrication technology, manufacturing of sandwich panels with various core configurations are made possible. Hence, recent studies are focused on axial compressive and bending responses of sandwich panels with different core materials and formations. Budiansky [14] and Wicks and Hutchinson [15] performed theoretical investigations of compressive response of metallic sandwich panels with metal foam and lattice cores, respectively. The results demonstrated that hat-stiffened panels are a better alternative compared to metal foam core sandwich columns in terms of axial performance and stiffness-to-weight. Côté et al. [16] and Biagi et al. [17] showed that pyramidal truss core and extruded aluminium corrugated core sandwich columns outperform the conventional hatstiffened panels in compression. Mozafari et al. [18, 19] studied the in-plane compressive responses of foam-filled aluminium honeycombs and observed much stronger load bearing capacity than single honeycombs. Paik et al. [20] investigated the strength characteristics of aluminium honeycomb sandwich panels with different cell thicknesses, core heights and panel aspect ratio through axial compression tests. More recently, Sun et al. [21] experimentally and numerically investigated the compressive strength, stiffness, energy absorption and collapse modes of honeycomb sandwich panels, and examined the effects of core heights, honeycombwall thickness and face-sheet thickness on the critical buckling loads of the sandwich structures.

Sandwich panels are used in construction industry in flooring, roofing, and wall applications [22]. With the recent global trend towards mid-rise to high-rise timber buildings, more attention is given to light-weight and sustainable wood products. Existing mass timber buildings commonly use cross-laminated-timber (CLT) floor diaphragms and load-bearing walls [23]. The current authors previously proposed the Bamboo Core Sandwich (BCS) panel, and examined its theoretical flexural performance compared to CLT [24, 25]. Single-layer (BCS- 
S) and double-layer (BCS-D) panels are depicted in Fig. 1 and are comprised of vertically aligned hollow bamboo rings (core) and commercial plywood laminates (skins). The hollow bamboo rings are bonded to the face skins using commercial adhesive. Bamboo is used in the core of the proposed sandwich panel due to: (1) its being a recyclable and sustainable natural material, (2) its rapid harvest (3-4 years from the time of planting), and (3) its outstanding stiffness-to-weight ratio. The current paper aims to complement the previous theoretical flexural study [24], and investigates the capacity and failure modes of the BCS panels under axial compressive load as well as combined bending and axial compression actions. This is done through experimental, numerical and simplified analytical approaches. The paper is concluded with a comparison between the axial compressive and combined compression and bending performances of the proposed BCS and conventional CLT panels.

\section{Materials and manufacturing}

\section{Samples}

In order to investigate the feasibility of the concept, two types of BCS panels: (a) single-layer (BCS-S) shown in Fig. 1a, and (b) double-layer (BCS-D) shown in Fig. 1b were manufactured and tested. As shown in Fig. 1a, the BCS-S panel is comprised of a single layer bamboo core sandwiched between two $7.2 \mathrm{~mm}$ structural plywood skins. The BCS-D panel (Fig. 1b) has two layers of bamboo rings sandwiched between $7.2 \mathrm{~mm}$ plywood skins, with bamboo rings separated by a $4 \mathrm{~mm}$ plywood laminate. The structural plywood laminates were commercially available and were manufactured to Australia/New Zealand Standard [26] from softwood veneers of plantation pine (Pinus radiata). The selected plywood IDs were 7-24-3 and 4-14-3. The numbering sequence in the ID gives from left to right: the nominal plywood thickness, the face veneer thickness multiplied by 10, and the number of plies in the assembly. For example, plywood ID 7-24-3, describes a $7 \mathrm{~mm}$ thick plywood, with $2.4 \mathrm{~mm}$ thick veneers on the top and bottom, and a total number of 3 veneer layers.

\section{Manufacturing}

To fabricate the BCS panels, mature Moso bamboo (Phyllostachys pubescens) culms with an average diameter of $100 \pm 20 \mathrm{~mm}$ and a wall thickness $(e)$ of $10 \mathrm{~mm}$ were selected. The bamboo culms were initially dried to a nominal 12\% MC (moisture content), and were then cut to rings with nominal heights of $70 \mathrm{~mm}$ for the BCS-S, and $32 \mathrm{~mm}$ for the BCS-D panels, respectively. Then, a timber frame with dimensions slightly smaller than the aspired panel dimensions was made. The timber frame was filled with the bamboo cores, adjusting the arrangement such that to keep the bamboo rings packed as closely as possible. A liquid single-component 
polyurethane adhesive (PURBOND HB S709) was applied to one side of the plywood skin, using the recommended spread rate $\left(180 \mathrm{~g} / \mathrm{m}^{2}\right)$. Prior to the application of the adhesive, the plywood surface was moistened with a light water spray. Then, the timber frame packed with bamboo rings was placed on top of the plywood skin and was cold pressed at a pressure of 0.8 $\mathrm{MPa}$, for a period of 120 minutes. Prior to the installation of the second side of the BCS panel, the first side was passed through the belt sander to even out the bamboo rings. The manufactured BCS panel was then left in the open air for 24 hours to reach the balanced moisture content.

Two panels (one BCS-S and one BCS-D panel) with length of ( $L=2,070 \mathrm{~mm}$ ), width of ( $b=570$ $\mathrm{mm})$ and nominal depths of $(d=85 \mathrm{~mm})$ were manufactured for the compression study. To investigate the shear bond strength (the bond between the bamboo rings and the plywood faces $), 12$ BCS-S panels with length of $(L=300 \mathrm{~mm})$, width of $(b=300 \mathrm{~mm})$ and nominal depths of $(d=85 \mathrm{~mm})$ were manufactured.

\section{Material properties (Probabilistic approach)}

From each plywood skin of the BCS-S and BCS-D panels, a total of five coupon (dog bone) samples were cut using a CNC machine. The coupon samples had nominal widths of $6.5 \mathrm{~mm}$ and gauge lengths of $64 \mathrm{~mm}$ and were tested according to the recommendations of ASTM D3500-14 [27]. The load was applied on the plywood coupons at a constant speed rate of 0.5 $\mathrm{mm} / \mathrm{min}$ to reach failure in 3-5 $\mathrm{min}$.

Due to limited number of plywood tensile tests and the large variation in the mechanical properties of the Pinus radiata used in the commercial plywood, a probabilistic approach was used to estimate the modulus of elasticity $(\mathrm{MOE})$ in the parallel-to-grain direction $\left(E_{L}\right)$ and the compressive strength in the parallel-to-grain direction $\left(\sigma_{c u}\right)$ of the Pinus radiata veneers [28, 29]. The cumulative log-normal distribution function (CDF) is

$$
C D F=\frac{1}{2}+\frac{1}{2} \operatorname{erf}\left[\frac{\ln x-\mu}{\sqrt{2} \sigma}\right]
$$

where the two parameters $\mu$ and $\sigma$ are the mean and standard deviation of the set of data values, respectively. By adopting recommended mean and standard deviation for $E_{L}$ and $\sigma_{c u}$ [30], the material properties of Pinus radiata are represented in Table 1 for the $30^{\text {th }}, 50^{\text {th }}$ and $70^{\text {th }}$ percentiles. The corresponding CDF curves (Eq. 1) are plotted in Fig. 2. The other properties were approximated based on their corresponding ratios to $E_{L}$ as recommended in [30]. 
To derive the mechanical properties of plywood skins from orthotropic properties of each veneer, a classical laminate theory tool (OSULaminates developed by Oregon State University) was utilised [31]. Material properties of the plywood skins obtained from OSULaminates, comprised of Pinus radiata veneers with properties listed in Table 1 for the corresponding percentiles, are presented in Table 2 . The average $E_{L}$ of plywood laminates obtained from the tensile tests are also represented in Table 2.

The material properties of bamboo cores were taken as the average values of Moso bamboo reported in [32], and are represented in Table 1.

\section{Experiments}

Shear bond tests

Adhesive spread rate study was conducted to evaluate the shear strength between bamboo and Pinus radiata plywood. To accomplish this, adhesive shear block testing was performed in adhesive spread rates of 180,360 and $540 \mathrm{~g} / \mathrm{m}^{2}$ for the BCS-S panel. For each adhesive spread rate, four BCS-S panels with dimensions of $300 \mathrm{~mm} \times 300 \mathrm{~mm}$ and depth of $85 \mathrm{~mm}$ were manufactured (Fig. 3). The panel dimensions were selected such that 3 intact bamboo rings could fit in the panel in each direction. Two timber planks were glued to the top and bottom surfaces of the panel. Using a $100 \mathrm{kN}$ Instron machine, a lateral displacement was imposed on the top plank, while the bottom plank was fixed in the machine's jaw. The shear bond strength was calculated as the failure load divided by the total wall-thickness area of the 9 bamboo rings.

\section{Axial compressive tests}

BCS-S and BCS-D panels $(2,070 \mathrm{~mm}$ height $\times 570 \mathrm{~mm}$ width $\times 85 \mathrm{~mm}$ depth $)$ were tested using a $500 \mathrm{kN}$ MTS universal testing machine. The test set-up and the boundary conditions are shown in Fig. 4. Solid steel shafts (rollers) were inserted between the BCS panel and the hydraulic jack on top and the base plate at the bottom. The shafts restrained the out of plane translation (in $y$ and $z$ directions shown in Fig. 4), and thus allowed buckling of the panel about its minor axis ( $y$-axis). The top platen was lowered at a constant rate of $1 \mathrm{~mm} / \mathrm{min}$, and the corresponding compressive load was recorded. A 3D Digital Image Correlation (DIC) system from Correlated Solutions Inc. [33] was used to measure the displacement and strain contours in the in-plane and out-of-plane directions. To do so, the entire panel surface on one side was brushed using a specific roller to provide the desired speckled pattern. A 2 camera/tripod assembly was located at a distance about 9 meters away from the panel, and was used to capture images of the speckle pattern during the axial loading. LED lights were placed in the vicinity 
of the panel to provide the required contrast. The DIC was synchronised with the MTS machine to provide the displacement and strain fields at any given load.

\section{Analytical and numerical models}

\section{Axial capacity of the BCS}

The Euler's expression of the critical elastic buckling load $\left(P_{E}\right)$ for the simply supported BCS panel with length of $L$ is given by

$$
P_{E}^{B C S}=\frac{\pi^{2}(E I)_{e q}}{L_{e}^{2}}
$$

where $(E I)_{e q}$ is the equivalent stiffness of the composite cross-section. $L_{e}$ is the effective length of the panel, and is equal to $L$ for the existing simply supported boundary conditions. The equivalent stiffness is calculated based on the properties of the transformed cross-section of the panel. Denoting the ratio $E_{\text {skin }} / E_{\text {core }}$ of the two moduli of elasticity by $N$, the transformed section is developed by replacing the skin material (plywood) with the core material (bamboo). The equivalent stiffness for the BCS panel becomes

$$
(E I)_{\text {eq. }}=E_{\text {core }}\left[\frac{b_{c} c^{3}}{12}+I_{\text {Skin-trans. }}\right]
$$

where $E_{c}$ is the modulus of elasticity of bamboo in the radial direction and $c$ is the core height (see Fig. 1). In a BCS panel, at any given cross-section cut along the span, the width of the bamboo core $\left(b_{c}\right)$ is almost equal to $2 e n_{b}$, where $e$ is the nominal bamboo wall-thickness and $n_{b}$ is the number of bamboo rings across the width of the panel. The moment of inertia of the transformed skin $\left(I_{\text {skin-trans. }}\right)$ can be expressed as

$$
I_{\text {skin-trans. }}=2\left(\frac{1}{12} b N t^{3}+(b N t)\left(\frac{c}{2}+\frac{t}{2}\right)^{2}\right), \quad b_{\text {trans. }}=b N, \quad N=\frac{E_{\text {skin }}}{E_{\text {core }}}
$$

where $E_{\text {skin }}$ is the modulus of elasticity of the plywood skin in the parallel-to-grain direction. In derivation of the elastic buckling capacity of the BCS panel $\left(P_{E V}^{B C S}\right)$, the shear deformation needs to be considered

$$
P_{E V}^{B C S}=\frac{P_{E}^{B C S}}{1+\frac{k P_{E}^{B C S}}{(A G)_{e q}}}
$$


The current authors derived analytical expressions for the equivalent shear stiffness $(A G)_{e q}$. and the Timoshenko shear coefficient $(\kappa)$ of a BCS panel [24]. For the sake of brevity, the expressions are shown here, and the avid reader is referred to [24] for the complete derivation of the equations.

$$
\begin{aligned}
& (A G)_{e q}=\left(b_{c} d\right) G_{c}+\left(b t_{\text {mid }-p l y}\right) G_{\text {mid }-p l y} \\
& \kappa=\frac{c}{(E I)_{e q}}\left(E_{\text {skin }} \frac{b t d}{2}+\frac{E_{\text {core }}\left(b_{c}\right)}{4}\left(\frac{c^{2}}{4}\right)\right)
\end{aligned}
$$

The second term in the RHS of $(A G)_{e q}$ in Eq. 6, corresponds to the BCS-D panel, where $t_{m i d}$-ply and $G_{m i d-p l y}$ are the thickness and shear modulus of the middle plywood in the BCS-D panel (see Fig. 1b).

The compression capacity of a stub BCS panel $P_{r}^{B C S}$ is

$$
P_{r}^{B C S}=\sigma_{Y}^{\text {plywood }} \cdot A_{\text {plywood }}+\sigma_{Y}^{\text {bamboo }} \cdot A_{\text {bamboo }}
$$

where $A_{\text {plywood }}$ is the sum of all cross-sectional areas of layers running parallel to the load, and $\sigma_{Y}$ is the yield strength parallel to the fibre direction.

\section{Axial capacity of the CLT}

The elastic buckling capacity of a CLT panel [34], considering the shear deformation is

$$
P_{E V}^{C L T}=\frac{P_{E}^{C L T}}{1+\frac{k P_{E}^{C L T}}{(A G)_{e f f}}}
$$

where $P_{E}$ is the Euler buckling load (Eq. 2), and $E=E_{05}$ and $I=I_{\text {eff }}$ are determined based on the properties of the layers oriented parallel to the axial load direction, only. $E_{05}$ is the modulus of elasticity for design of compression members, and is equal to $0.82 E$ for machine stress-rated (MSR) lumbers [34]. For rectangular cross-sections the shear factor $k$ of 1.2 is adopted [34]. The effective bending stiffness $(E I)_{\text {eff }}$ (similar to $(E I)_{e q}$ in Eq. 2) and the shear stiffness $(A G)_{\text {eff }}$ of a CLT panel with alternating orthogonal layers can be determined via the shear analogy method $[24,35]$ 


$$
\begin{aligned}
& (E I)_{\text {eff }}=\sum_{i=1}^{n} E_{i} \cdot b_{i} \cdot \frac{h_{i}^{3}}{12}+\sum_{i=1}^{n} E_{i} \cdot A_{i} \cdot z_{i}^{2} \\
& (A G)_{\text {eff }}=\frac{d_{a}{ }^{2}}{\left[\left(\frac{h_{1}}{2 \cdot G_{1} \cdot b}\right)+\left(\sum_{i=2}^{n-1} \frac{h_{i}}{G_{i} \cdot b_{i}}\right)+\left(\frac{h_{n}}{2 \cdot G_{n} \cdot b}\right)\right]}
\end{aligned}
$$

where $E_{i}$ is the modulus of elasticity of layer $i$, and $b_{i}, h_{i}$ and $A_{i}$ are the width, thickness and cross-sectional area of each individual layer, respectively. The distance between the centroid of each layer and the centroid of the total cross-section of the CLT panel is $z_{i}$. Subscripts 1 and $n$ correspond to the top and bottom layers, respectively. As recommended in [34], in the transverse layers, the modulus of elasticity $E_{i}$ is multiplied by $1 / 30$. The shear modulus of the laminations $\left(G_{i}\right)$, normally taken as $E_{i} / 16$ for the longitudinal layers. To account for the rolling shear effect, the shear modulus in the transverse direction is divided by 10 . Based on the recommendations of the Canadian Standards Association (CSA) [34] the unfactored compressive design capacity of the CLT panel $P_{r}^{C L T}$ is

$$
P_{r}^{C L T}=f_{c} A_{e f f} K_{Z c} K_{C}
$$

where $f_{c}$ is the specified strength in compression parallel to the grain of the laminations oriented parallel to the axial load. $A_{\text {eff }}$ is the effective cross-sectional area of the panel accounting only for the layers with laminations oriented parallel to the axial load. $K_{z c}$ and $K_{c}$ are the size and slenderness factors, respectively [34]

$$
K_{Z c}=6.3\left(\sqrt{12} r_{e f f} L\right)^{-0.13} \leq 1.3 \quad, \quad K_{C}=\left[1.0+\frac{f_{c} K_{Z c} C_{C}^{3}}{35 E_{05}}\right]
$$

where $r_{\text {eff }}$ and $C_{c}$ are the effective radius of gyration and the slenderness ratio of a simply supported CLT panel with length $L$, respectively.

$$
r_{\text {eff }}=\sqrt{\frac{I_{\text {eff }}}{A_{\text {eff }}}} \quad, \quad C_{C}=\frac{L_{e}}{\sqrt{12} r_{\text {eff }}}
$$


CLT panels subject to combined out-of-plane bending and compressive axial load should satisfy the following interaction equation [34]

$$
\frac{P}{P_{r}^{C L T}}+\frac{M}{M_{r}^{C L T}}\left[\frac{1}{1-\frac{P}{P_{E V}^{C L T}}}\right] \leq 1
$$

where $P$ and $M$ are the applied compressive axial load and applied bending moment, respectively. $M_{r}^{C L T}$ is the unfactored out-of-plane bending moment design resistance of the CLT panel

$$
M_{r}^{C L T}=f_{b} S_{e f f} K_{r b} \quad, \quad S_{e f f}=\frac{2(E I)_{e f f}}{E h}
$$

where $f_{b}$ is the specified bending strength of laminations in the longitudinal layers. $S_{\text {eff }}$ is the effective out-of-plane section modulus of CLT panel. $E$ and $h$ are the modulus of elasticity of laminations in the longitudinal layers and thickness of the panel, respectively. The adjustment factor for bending moment resistance of CLT panels, $K_{r b}$ is equal to 0.85 [34].

\section{Finite element analysis (FEA)}

Finite element analysis (FEA) was conducted using ANSYS 19.0 [36] to calculate the compressive capacities of the BCS panels with different lengths and core configurations. In the FEA, the diameter and wall-thickness of all bamboo rings were identical (Fig. 1). Moreover, to fit in intact bamboo rings, the width of the panel was taken as $600 \mathrm{~mm}$ (was $570 \mathrm{~mm}$ in the experiment). The plywood veneers and the bamboo rings were meshed using eight node solid elements SOLID186 [36]. The experimental results (will be discussed later) did not show any de-bonding between bamboo rings and plywood faces in the pre-buckling (ultimate capacity) stage. Therefore, in the FEA, no-slip contact model was adopted between the core and the faces. However, in the FEA, the stresses in the contact elements at each loading were compared to the shear bond test results. Plywood veneers had one element along the veneer thickness and the bamboo core was discretised with two and seven elements along the wall-thickness $(e)$ and core height $(c)$, respectively.

Fig. 5a shows the FEA mesh and boundary conditions of a BCS-S panel. In order to replicate the experimental boundary conditions (Fig. 4), thick steel discs were attached to either ends of the BSC panel in the FE model. The discs on the top and bottom were restrained about 
translation in $y$ and $z$ directions and rotation about $x$ and $z$ directions, to mimic simply supported bending about minor axis. The bottom disc was fixed in the $x$ direction, while the top disc could freely move in the longitudinal direction.

To account for the plastic behaviour of the plywood in compression, the Hill's orthotropic bilinear hardening [37] definition was adopted in the FEA. The stress potential in the Hill criterion is expressed as

$$
\sigma_{e}=\sqrt{F_{R R}\left(\sigma_{x}-\sigma_{y}\right)^{2}+F_{L L}\left(\sigma_{y}-\sigma_{z}\right)^{2}+F_{T T}\left(\sigma_{z}-\sigma_{x}\right)^{2}+2 N_{L T} \tau_{x y}^{2}+2 N_{T R} \tau_{y z}^{2}+2 N_{R L} \tau_{x z}^{2}}
$$

$F$ and $N$ are constants obtained from material tests conducted in different orientations

$$
\begin{gathered}
F_{i j}=\left[\frac{\left(\sigma_{0}\right)^{2}}{2}\right]\left[\frac{1}{\left(\sigma_{j j}^{y}\right)^{2}}+\frac{1}{\left(\sigma_{k k}^{y}\right)^{2}}-\frac{1}{\left(\sigma_{i i}^{y}\right)^{2}}\right]=\frac{1}{2}\left[\frac{1}{R_{j j}{ }^{2}}+\frac{1}{R_{k k}{ }^{2}}-\frac{1}{R_{i i}{ }^{2}}\right]\left\{\begin{array}{l}
i=L, T, R \\
j=T, R, L \\
k=R, T, L
\end{array}\right\} \\
N_{i j}=\frac{3}{2}\left[\frac{\left(\tau_{0}\right)^{2}}{\sigma_{i j}^{y}}\right]=\frac{3}{2}\left[\frac{1}{R_{i j}{ }^{2}}\right](i \neq j=L, T, R)
\end{gathered}
$$

and $\sigma_{i i}^{y}$ and $\sigma_{i j}^{y}$ correspond to the normal and shear yield stresses, where subscripts $L, T$ and $R$, are associated with the longitudinal, tangential and radial directions, respectively. $R_{i j}$ are the yield ratios which relate the yield level for stress components $\sigma_{i j}^{y}$, to the reference yield stress $\sigma_{o}$ of the material. The yield ratios are

$$
\begin{gathered}
R_{i j}=\left\{\begin{array}{ll}
\frac{\sigma_{i j}^{y}}{\sigma_{0}}, & \text { if } i=j \\
\frac{\sigma_{i j}^{y}}{\tau_{0}}, & \text { if } i \neq j
\end{array}\right\} \\
\tau_{0}=\frac{\sigma_{0}}{\sqrt{3}}
\end{gathered}
$$

and are represented in Table 3 for different percentiles. Tangent modulus $\left(E_{T}\right)$ of $345 \mathrm{MPa}$ is adopted [38]. The elastic-plastic stress-strain relationship of timber in compression used in the FEA is shown in Fig 5b. The material properties of the bamboo rings were assigned using local cylindrical coordinate systems. Since the current study investigates the buckling capacity of 
the wall panels (not the post-buckle response), elastic behaviour was assumed for plywood in tension.

The ultimate buckling capacities of the panels are sensitive to the shape of the geometric imperfections. To acquire the geometric imperfect shapes, linear Eigenvalue buckling analyses were performed and the first two buckling mode shapes (mode I and mode II) were developed. These buckling modes were then imposed as initial imperfections to the model, and nonlinear FEA were conducted. Normalised amplitude of the initial imperfection adopted in all models was equal to $\delta / L=2 \times 10^{-4}$. In the axial compressive study, firstly, the imperfection was imposed to the FEA model, and then an axial shortening displacement was applied to the top disc through a master node.

In the combined loading study, two load paths were investigated. The first load path was axial compressive force followed by bending, $p \rightarrow w$. The axial load was maintained as a fraction of the axial capacity found in the axial compressive study. Then a lateral wind pressure $(w)$ was gradually applied to the panel in the transverse direction, until buckling was observed. In the second load path, the lateral wind pressure of $w=2 \mathrm{kPa}$ (typical design wind pressure in noncyclonic regions of East coast Australia [39]) was maintained while the axial shortening was induced, $w \rightarrow p$. The axial force corresponding to the initiation of the buckle was calculated.

In all of the FEA results, the capacity of the panel corresponds to the minimum load associated with one of these failure modes: (1) onset of yield in the plywood skins using the Hill's criteria (Eq. 15), (2) the bond stress between the plywood and the bamboo core exceeding the bond strength measured in the experiment (section 5.1), and (3) global buckling of the panels or local buckling of the skin.

\section{Results and discussion}

\subsection{Shear bond strength}

The ultimate loads at failure of the shear bond tests are represented in Table 4. The shear strength at the bond is found by dividing the ultimate load by the bamboo wall-thickness area. It can be seen that doubling or tripling the glue spread rate, does not translate into a significant increase in the bond strength. Hence, in the manufacturing of the panels, the recommended spread rate $180 \mathrm{~g} / \mathrm{m}^{2}$ was adopted. At this spread rate, the average shear strength at the bambooplywood contact is $0.99 \mathrm{MPa}$.

\subsection{Axial compression}




\section{Comparison between experimental, analytical and FEA results}

The first two buckling mode shapes (I and II) of the BCS-S and BCS-D panels obtained from finite element Eigen buckling analyses are shown in Fig. 6. The first modes (mode I) in either panels are the classic Euler mode shape. Mode II of the BCS-S is the classical double-curved sinusoidal shape, whereas, in the BCS-D panel, mode II is local buckling of the plywood skin.

Figs. 7 and 8 compare the load vs. lateral displacement and longitudinal strains at the midheight of the BCS-S and BCS-D panels, respectively, obtained from the experimental and FEA results. In all FEA models, and at different load stages, failures in: (1) buckling, (2) yield of plywood (Eq. 15), and (3) shear bond failure were checked. All samples failed in buckling. The stress ratio $\left(\sigma_{e} / \sigma_{o}\right)$ at ultimate loads of each panel are shown in Figs. 7a and 8a. It can be seen that at ultimate loads, almost all panels depict yield in the plywood veneer. This is followed by buckling of the panel. The analytical axial compressive capacity of the BCS panels $\left(P_{E V}^{B C S}\right)$ from Eq. 5 are also shown in the figure for comparison. The failed samples are shown in Fig. 9.

As shown in Fig. 7a, in the BCS-S panel the load increases monotonically with negligible lateral displacement. At the onset of buckling, the lateral displacement grows significantly as the axial load drops. Similar trend is observed in the load-strain response of Fig. 7b. The ultimate capacity of the BCS-S panel obtained from the experiment is $179 \mathrm{kN}$. The analytical formulation (Eq. 5) does not include geometric imperfections and material nonlinearities, and provides upper bounds of capacities. As seen in Fig. 7a, the analytical predictions using the $30^{\text {th }}$ percentile, overestimates the experimental result by $12.1 \%$.

In order to capture the FEA response of the BCS-S panels, models with different MOE and MOR percentiles $\left(30^{\text {th }}, 50^{\text {th }}\right.$ and $\left.70^{\text {th }}\right)$ and with mode I and II imperfections (Fig. 6a) are produced. As shown in Fig.7a, using mode I imperfections, ultimate capacities of $158.7 \mathrm{kN}$, $174.4 \mathrm{kN}$ and $194.3 \mathrm{kN}$ corresponding to $30^{\text {th }}, 50^{\text {th }}$ and $70^{\text {th }}$ percentiles, respectively, are calculated. As shown in Fig. 7b, the linear load-strain response of the FEA-Mode I with $30^{\text {th }}$ percentile matches with the experimental response. However, the ultimate capacity of the FEAis $11.36 \%$ lower than the experimental observation. Whereas, when buckling mode shape II (Fig. 6a) is used as the initial imperfection (with $30^{\text {th }}$ material), the load displacement/strain response matches the experimental response, and the ultimate load is only $0.48 \%$ lower than the experiment. Moreover, using the FEA Mode II- $30^{\text {th }}$ model, similar plateaus are observed in the load displacements/strains at the ultimate load, as those seen in the experiment. The plateau 
is associated with the yield in compression of the plywood faces. The failed BCS-S panel is shown in Fig. 9a, and the local failure points are circled. It can be seen that the local failure points of the physical test are not at the mid-span, and are closer to the maximum lateral displacement/strain contours suggested by the FEA.

Fig. 8 shows results of the BCS-D panels. The ultimate capacity of the BCS-D panel is 190.8 $\mathrm{kN}$, and it is $6.6 \%$ higher than the BCS-S panel. The analytical predictions are larger than the experimental results. Amongst the FEA results, those of the FEA-Mode I-70 ${ }^{\text {th }}$ are in a good agreement with the experimental results with $4.6 \%$ difference in the peak load. The snapthrough buckle response of Fig. 8b corresponds to the buckling failure shown in Fig. 9b. Unlike the deformed shape at failure of the FEA, the location of the failure in the tested BCS-D panel is not exactly in the middle. That may be related to local material imperfections, and explains the differences between the ultimate loads between the FEA and the experiment.

\section{Optimised core configuration}

The FEA results in the previous section showed good agreement with the experimental results. Using the validated FEA, an effort is made to optimise the core configuration in the BCS panels. Assumed core configurations are depicted in Fig. 10a. All panels have similar depth of $84.4 \mathrm{~mm}$ (same as the physical model). Using the validated FEA, and assuming buckling mode shape I (shown in Fig. 6) imposed as the initial imperfection, with $50^{\text {th }}$ percentile material properties, the load-axial displacement response of each configuration is calculated and is plotted in Fig. 10b. To benchmark, results of the BCS-S and BCS-D panels are also shown.

The most superior stiffness and ultimate capacity correspond to a single layer design with the plywood thickness doubled (BCS-S1). This sample can be manufactured by gluing a 3 -strand commercial plywood to the existing skins. The capacity of BCS-S1 is $79.5 \%$ higher than the BCS-S, and 71.4\% larger than the BCS-D panels. By using identical plywood thickness (BCSD1), the stiffness and ultimate capacity of the BCS-D panel is increased by $62.15 \%$ and $6.85 \%$, respectively. Moreover, as seen in the response of BCS-D1 in Fig. 10b, using identical plywood thickness stabilises the post-bucking response of the panel.

Tripling the core layers (BCS-T) increases the ultimate capacity by $20 \%$ and stiffness by $26.7 \%$, compared to BCS-D panel. By adding a gap between the bamboo cores (68 $\mathrm{mm}$ along the width of the panel) in a single layer concept (BCS-S2), the number of bamboo core 
decreases by $33.3 \%$, while no significant change in stiffness and ultimate capacities are observed.

In the BCS-S2 (-30\%) panel, the mechanical properties of the bamboo is reduced by $30 \%$. No significant change in stiffness and buckling capacity is observed between this panel and the BCS-S2 panel.

\subsection{Comparison between BCS and CLT panels}

\section{Axial compression}

Ultimate capacities of BCS-S and BCS-D panels at different lengths are calculated using FEA with mode shapes I and II imperfections. Results are shown in Fig. 11, where the ultimate load $(P)$ is normalised to the corresponding compressive capacity of the panel $\left(P_{r}\right)$, given in Eq. 7 to give the strength index SI $\left(S I=P / P_{r}\right)$. All panels have similar width $(600 \mathrm{~mm})$, and depth (84.4 mm). Lengths of the panels vary between $300 \mathrm{~mm}$ and $3000 \mathrm{~mm}$, hence the nondimensional slenderness ratio $\left(\lambda_{B C S}=\sqrt{12} L / d\right)$ changes from 12.3 to 123.1 .

In all FEA models, and at different load stages, failure in (1) buckling, (2) yield of plywood (Eq. 15), and (3) shear bond failure were checked. All samples failed either in buckling or in shear bond failure. None of the samples showed a pre-buckle yield failure in plywood. The data points shown in solid fill correspond to the shear bond (interface) failure. The interface failure is assumed to occur when the shear stress between bamboo cores and plywood skins exceeds $0.99 \mathrm{MPa}$, (tested shear bond strength in Table 4). As shown in Fig. 11a, there is a significant difference in ultimate capacity of BCS-S panels between Mode I and Mode II imperfections. At large slenderness ratios $(\lambda>100)$, the capacity of the BCS-S panel from Mode I is substantially lower than the Mode II. This suggests that the axial capacity of the BCS-S panel is very sensitive to the fabrication tolerances. Axial capacity of the BCS-D panel is not as sensitive to the initial imperfection mode. All the BCS-S (Mode I) panels experience failure in global buckling. However, in BCS-S (Mode II) shear interface failure is observed at panel lengths $L<1800 \mathrm{~mm}$. The two short BCS-D panels ( $L=300 \mathrm{~mm}$ and $L=600 \mathrm{~mm}$ ) experience shear interface failure, while the remaining panels fail in overall buckling.

Slenderness curves are developed for the BCS panels based on the minimum capacity (calculated from the FEA with respective initial imperfection mode, shown in Fig. 11a), and are plotted in Fig. 11b. The slenderness curve of the panel with the optimum core configuration 
(BCS-S1) is plotted as well. In all panels, $50^{\text {th }}$ percentile material properties are incorporated into the FEA.

For sake of comparison, the slenderness curve of a CL3/85 XLam CLT product [40] is shown as well. The $C L 3 / 85$ panel consists of three layers of sawn boards with a total thickness of 85 $\mathrm{mm}(20 \mathrm{~mm} / 45 \mathrm{~mm} / 20 \mathrm{~mm})$. The two outermost layers (1 and 3) are aligned in the span direction (parallel to axial compressive load), and the middle layer is perpendicular to the span direction. The unfactored compressive design capacity of the CLT panels under axial load is calculated from Eq. 10, based on the material properties of the CLT laminations listed in Table 5. The parallel to grain modulus of elasticity $\left(E_{L}\right)$, bending strength $\left(f_{b}\right)$ and compressive strength $\left(f_{c}\right)$ are taken from XLam design guide [40]. The unfactored compressive design capacity of the $C L 3 / 85$ (Eq. 10) with length of 2,070 mm (and width of $570 \mathrm{~mm}$ ) and based on the material properties of Table 5 , is $326.2 \mathrm{kN}$.

In Fig. 11b, to calculate the strength index SI of the CLT panels, the unfactored compressive design capacity $P_{r}$ from Eq. 10, is normalised to the corresponding compressive capacity of a short CLT panel (assuming $K_{z c}$ and $K_{c}$ are equal to one in Eq. 10).

As shown in Fig. 11b, the CLT curve is an upper bound for all BCS panels. The next best is the BCS-S1 panel. However, it can be seen that at large slenderness ratios $(\lambda>100)$, which is within the typical column lengths in a building $(L=3 \mathrm{~m})$, the BCS panels achieve strength indexes (SI) close to the CLT panel. The shear interface failure mode only occurs in stubby BCS panels $(\lambda<40)$. The governing failure mode in all BCS panels with $(\lambda>40)$ is the Euler column buckle mode.

\section{Combined axial compression and bending ( $p \rightarrow$ w load path)}

Capacity of the BCS panels with length $(L=2,100 \mathrm{~mm})$ under combined loading is studied using FEA with $50^{\text {th }}$ percentile material properties. The FEA is conducted in two load steps. In the $p$ $\rightarrow w$ load path, and in the first load step, the axial force in the panel is maintained at $30 \%, 50 \%$ and $70 \%$ of the axial capacity of the corresponding panel calculated from pure compression FEA study in the previous sections. In the second load step, a uniform lateral wind pressure $w$ is applied to one face of the plywood, and is increased until the failure is observed. Lateral wind pressures $w$ for each panel at the predetermined axial load are represented in Table 6 and are plotted in Fig. 12. Combined loading results of the $C L 3 / 85$ are also shown in Fig. 12. In the CLT panel, the moment at failure $M$ is calculated from the interaction equation (Eq. 13), and 
the equivalent lateral load $w$ is found assuming simply supported boundary conditions ( $\left.w=8 M / L^{2}\right)$.

A shown in Fig. 12 and represented in Table 6, at small normalised axial loads (30\%), lateral capacity of the BCS-S1 panel is $47.6 \%$ and $83.6 \%$ larger than those of the BCS-D and BCS-S panels, respectively. The difference gets smaller as the axial load approaches the full capacity of the panel in compression. Normalised capacity of the CLT panel is closer to the capacity of the BCS-S panel. The failure modes of all BCS panels are shear interface failure (due to excessive bending) as represented in Table 6 .

\section{Combined axial compression and bending $(w \rightarrow$ p load path)}

In this load path, a $2 \mathrm{kPa}$ lateral wind pressure (typical design wind pressure in non-cyclonic regions of East coast Australia) is applied, and the axial shortening is imposed until failure is observed. Results are presented in Table 6. All BCS panels fail in Euler column buckling mode. The normalised load capacity of the BCS-S, BCS-D, and BCS-S1 panels are 0.81, 0.74 and 0.77 of the axial compressive capacity under pure compression in each panel, respectively. The corresponding normalised load capacity of the CL3/85 is 0.67 (see Fig. 12).

\section{Conclusions}

Novel timber panels with commercial plywood faces and bamboo ring cores were manufactured and tested in axial compression and in the shear bond strength. In the shear bond tests, square panels with width of $300 \mathrm{~mm}$ and depth of $85 \mathrm{~mm}$ were manufactured and tested. Shear bond strength test results showed that increasing the polyurethane adhesive spread rate, does not enhance the shear bond strength significantly. Therefore, a spread rate of $180 \mathrm{~g} / \mathrm{m}^{2}$ with shear strength at the bamboo-plywood contact of $0.99 \mathrm{MPa}$ was adopted in the manufacturing of large panels.

Two types of panels were tested in axial compression, a single-layer (BCS-S) and a doublelayer (BCS-D). The panels had length of $2,070 \mathrm{~mm}$, width of $570 \mathrm{~mm}$, and depth of $85 \mathrm{~mm}$. The axial test capacities of the BCS-S and BCS-D panels, were shown to be $179.0 \mathrm{kN}$ and $190.8 \mathrm{kN}$, respectively. At similar dimensions, the unfactored axial compressive design capacity [34] of a CLT panel (CL3/85) is $326.2 \mathrm{kN}$. However, the BCS-S and BCS-D panels weigh $19.42 \mathrm{~kg} / \mathrm{m}^{2}$ and $20.15 \mathrm{~kg} / \mathrm{m}^{2}$, which is $55.7 \%$ and $54 \%$ less than the CLT panel (with a nominal weight of $43.85 \mathrm{~kg} / \mathrm{m}^{2}$ ), respectively. Therefore, the ultimate capacity to weight ratio 
of BCS-S and BCS-D panels are 24\% and 27.3\% higher than a conventional CLT panel (CL3/85), respectively.

The FEA study with probabilistic material definitions and different initial geometric imperfections revealed that the buckling capacity of the BCS panels are significantly affected by the plywood material properties. Effect of geometric imperfection (imposed as Eigen buckling mode shapes in the FE models) was shown to be more substantial in the capacity of the BCS-S panel. The parametric FEA study with various core configurations revealed that the highest axial stiffness and capacity is gained using a single-layer panel with the plywood thickness doubled (BCS-S1). While, a BCS-D panel with identical plywood thicknesses showed a more stabilised post-buckling response. Reducing the material properties of bamboo by $30 \%$ did not affect the stiffness and buckling capacity of the panels.

In order to study the length effect, slenderness curves were developed for the BCS and CLT panels. Short BCS-S and BCS-D depicted failure in bond between the bamboo rings and the plywood faces. Whereas, column buckling failure was observed in long wall panels. The slenderness curve of the CLT panel was shown to be an upper bound of BCS panels at all slenderness ratios. However, at large slenderness ratios $(\lambda>100)$, which is within the typical column lengths of a building ( $\mathrm{L}=3 \mathrm{~m})$, the BCS panels achieved normalised axial capacities close to the CLT (CL3/85) panel.

In the combined loading studies, two different load paths were considered: (1) compression then lateral wind, and (2) lateral wind then compression. In the first load path $(p \rightarrow w)$, the axial loads in the panels were maintained at fractions of the panel's ultimate axial load capacity. Then the lateral wind load was gradually increased until failure occurred. All BCS panels failed in shear bond strength. It was understood that at small axial loads, the BCS panels have larger capacity compared to the CLT panel. The difference almost vanished as the axial load approached the full capacity. In the second load path $(w \rightarrow p)$, initially a $2 \mathrm{kPa}$ lateral wind pressure was applied, then axial force was imposed until failure occurred. All the BCS panels failed in global buckling. The normalised axial capacity of the BCS-S and BCS-D panels were $20.9 \%$ and $10.45 \%$ larger than the CLT panel, respectively. The BCS-S1 panel (with optimised core configuration) showed $14.92 \%$ increase in the combined capacity compared to the CLT panel.

\section{References}


[1] Zhang, F., Liu, W., Ling, Z., Fang, H., \& Jin, D. Mechanical performance of GFRP-profiled steel sheeting composite sandwich beams in four-point bending. Composite structures 2018; 206: $921-932$.

[2] Sohel, K., \& Liew, J. R. Steel-Concrete-Steel sandwich slabs with lightweight core - Static performance. Engineering structures 2011; 33(3): 981-992.

[3] Manalo, A., Aravinthan, T., Karunasena, W., \& Islam, M. Flexural behaviour of structural fibre composite sandwich beams in flatwise and edgewise positions. Composite structures 2010; 92(4): 984-995.

[4] Shams, A., Stark, A., Hoogen, F., Hegger, J., \& Schneider, H. Innovative sandwich structures made of high performance concrete and foamed polyurethane. Composite structures 2015; 121: 271-279.

[5] Jensen, K., Al-Rubaye, S., Thomas, R. J., \& Maguire, M.. Mechanics-Based model for elastic Bending, Axial, thermal Deformations, and asymmetry of concrete composite sandwich wall panels. Structures 2020; 23, 459-471.

[6] Dawood, M., Ballew, W., \& Seiter, J. Enhancing the resistance of composite sandwich panels to localized forces for civil infrastructure and transportation applications. Composite structures 2011; 93(11): 2983-2991.

[7] Mamalis, A., Spentzas, K., Manolakos, D., Ioannidis, M., \& Papapostolou, D. Experimental investigation of the collapse modes and the main crushing characteristics of composite sandwich panels subjected to flexural loading. International journal of crashworthiness 2008; 13(4): 349-362.

[8] Reyes, G. Static and low velocity impact behavior of composite sandwich panels with an aluminum foam core. Journal of Composite Materials 2008; 42(16): 1659-1670.

[9] Fam, A., \& Sharaf, T. Flexural performance of sandwich panels comprising polyurethane core and GFRP skins and ribs of various configurations. Composite structures 2010; 92(12): 2927-2935.

[10] Crupi, V., Epasto, G., \& Guglielmino, E. Collapse modes in aluminium honeycomb sandwich panels under bending and impact loading. International Journal of Impact Engineering 2012; 43: 6-15.

[11] Tuwair, H., Volz, J., ElGawady, M., Mohamed, M., Chandrashekhara, K., \& Birman, V. Behavior of GFRP bridge deck panels infilled with polyurethane foam under various environmental exposure. Structures 2016; 5, 141-151.

[12] Wang, Z., Jing, L., Ning, J., \& Zhao, L. The structural response of clamped sandwich beams subjected to impact loading. Composite structures 2011; 93(4): 1300-1308.

[13] Mastali, M., Valente, I. B., \& Barros, J. A. Flexural performance of innovative hybrid sandwich panels with special focus on the shear connection behavior. Composite structures 2017; 160: 100-117.

[14] Budiansky, B. On the minimum weights of compression structures. International Journal of Solids and Structures 1999; 36(24): 3677-3708. 
[15] Wicks, N., \& Hutchinson, J. W. Optimal truss plates. International Journal of Solids and Structures 2001; 38(30-31): 5165-5183.

[16] Cote, F., Biagi, R., Bart-Smith, H., \& Deshpande, V. S. Structural response of pyramidal core sandwich columns. International Journal of Solids and Structures 2007; 44(10): 35333556.

[17] Biagi, R., \& Bart-Smith, H. In-plane column response of metallic corrugated core sandwich panels. International Journal of Solids and Structures 2012; 49(26): 3901-3914.

[18] Mozafari, H., Molatefi, H., Crupi, V., Epasto, G., \& Guglielmino, E. In plane compressive response and crushing of foam filled aluminum honeycombs. Journal of Composite Materials 2015; 49(26): 3215-3228.

[19] Mozafari, H., Khatami, S., Molatefi, H., Crupi, V., Epasto, G., \& Guglielmino, E. Finite element analysis of foam-filled honeycomb structures under impact loading and crashworthiness design. International journal of crashworthiness 2016; 21(2): 148-160.

[20] Paik, J. K., Thayamballi, A. K., \& Kim, G. S. The strength characteristics of aluminum honeycomb sandwich panels. Thin-Walled Structures 1999; 35(3): 205-231.

[21] Sun, Z., Shi, S., Guo, X., Hu, X., \& Chen, H. On compressive properties of composite sandwich structures with grid reinforced honeycomb core. Composites Part B: Engineering 2016; 94: 245-252.

[22] Karlsson, K. F., \& TomasÅström, B. Manufacturing and applications of structural sandwich components. Composites Part A: Applied Science and Manufacturing 1997; 28(2): 97-111.

[23] Reynolds, T., Casagrande, D., \& Tomasi, R. Comparison of multi-storey cross-laminated timber and timber frame buildings by in situ modal analysis. Construction and building materials 2016; 102: 1009-1017.

[24] Darzi, S., Karampour, H., Gilbert, B. P., \& Bailleres, H. Numerical study on the flexural capacity of ultra-light composite timber sandwich panels. Composites Part B: Engineering 2018; 155: 212-224.

[25] Darzi, S., Karampour, H., Gilbert, B. P., \& Bailleres, H. Flexural behaviour of a novel bamboo-plywood sandwich composite panel. Paper presented at the 2018 World Conference on Timber Engineering (WCTE 2018), Seoul, Republic of Korea.

[26] Australian/New Zealand Standard. AS/NZS 2269.0:2012 plywood-structural Part 0: specification. 2012.

[27] ASTM D3500-14, Standard Test Methods for Structural Panels in Tension, ASTM International, Pennsylvania, USA, 2014.

[28] JCSS (2006) Probabilistic Model Code. Part III - Resistance Models. Ch. 3.5 Properties of Timber, Joint Committee on Structural Safety, p. 6.

[29] Dahl, K. B. (2009). Mechanical properties of clear wood from Norway spruce. Retrieved from http://brage.bibsys.no/xmlui/handle/11250/236422. 
[30] Ross RJ. Wood handbook: wood as an engineering material vol. 509. USDA Forest Service, Forest Products Laboratory; 2010. p. 1. General Technical Report FPL-GTR190.

[31] John A. Nairn. OSULaminates (version version 6.0). Oregon state university; 2015.

[32] Chung K, Yu W. Mechanical properties of structural bamboo for bamboo scaffoldings. Eng Struct 2002; 24(4):429-42.

[33] Correlated SOLUTIONS. (2019). VIC-3D Testing Guide. Retrieved from http://correlatedsolutions.com/

[34] Canadian Standards Association (CSA). CSA-O86-2016 Engineering Design in Wood; 2016 update to the 2014 standard edition; CSA Group: Mississauga, ON, Canada, 2016.

[35] Blass H. J., and P. Fellmoser. 2004. Design of solid wood panels with cross layers. In Proceedings of the 8th World Conference on Timber Engineering, June 14-17, 2004, Lahti, Finland, 2:543-548.

[36] ANSYS 19.0 release. A.I., 275 technology drive, Canonsburg, PA 15317.

[37] Hill R. The mathematical theory of plasticity. Oxford (NY): Oxford University Press; 1950

[38] Alam P. The reinforcement of timber for structural applications and repair PhD thesis Dept of Mech. Eng. University of Bath; 2004.

[39] Australian/New Zealand Standard. AS1170.2:2011, structural design action, Part 2: Wind actions, 2011.

[40] XLam. Designing with XLam cross laminated timber. 2016. New Zealand Design Guide Version 2.1. 


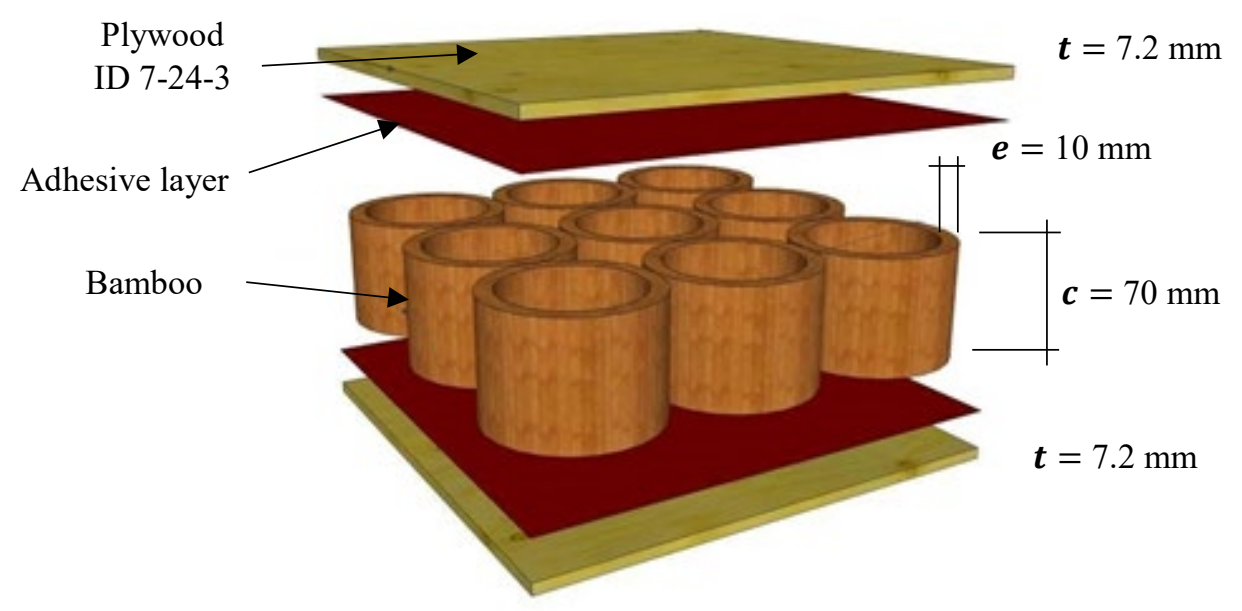

(a)

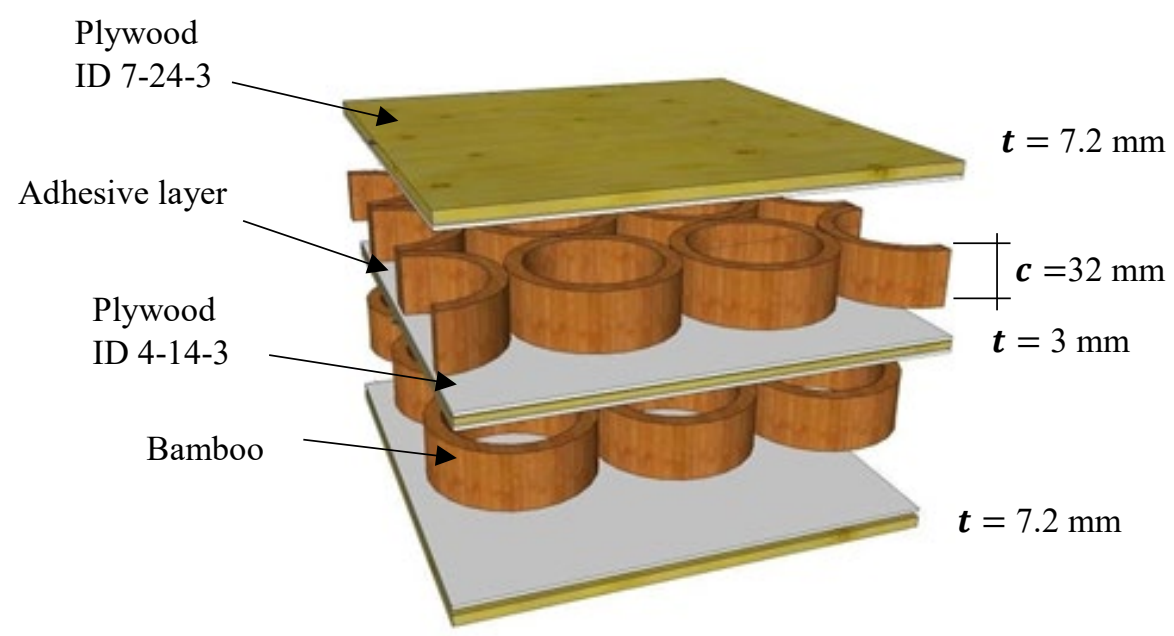

(b)

Fig. 1. Schematic illustrations of: (a) the single-layer panel (BCS-S), and (b) double-layer panel (BCS-D). 


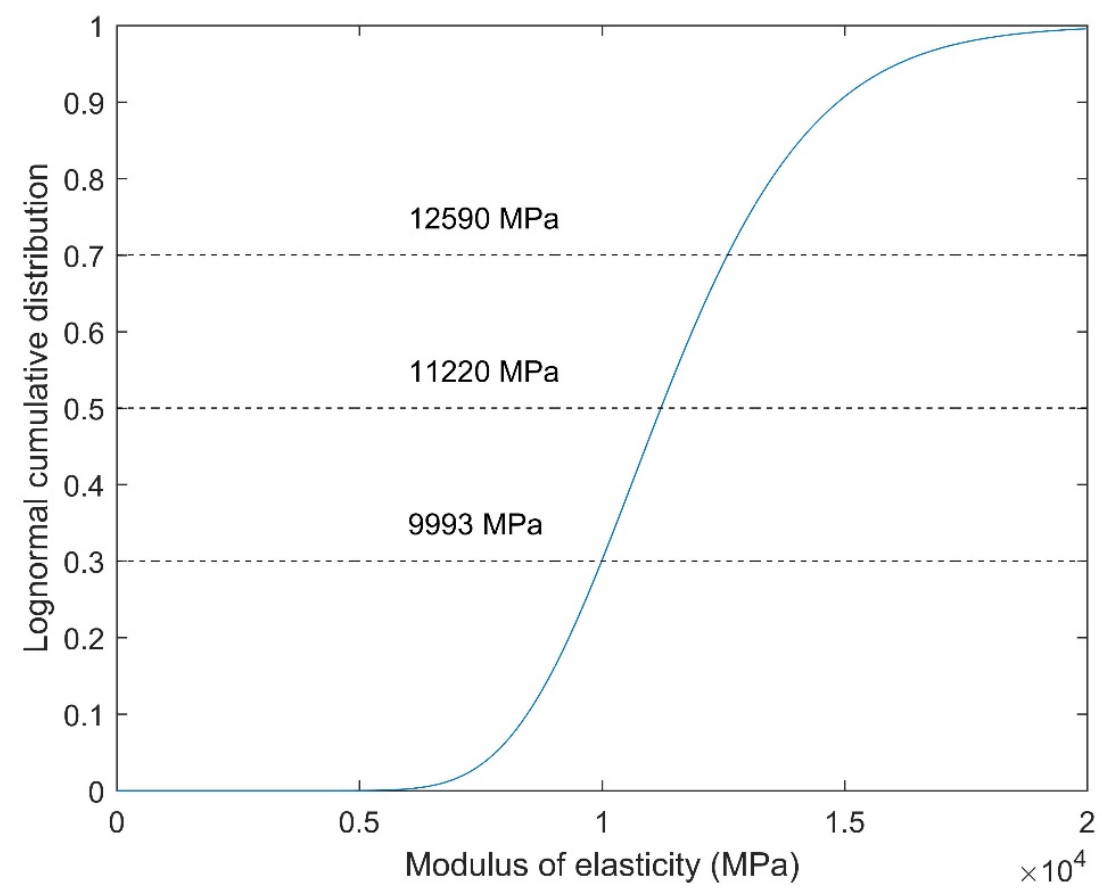

(a)

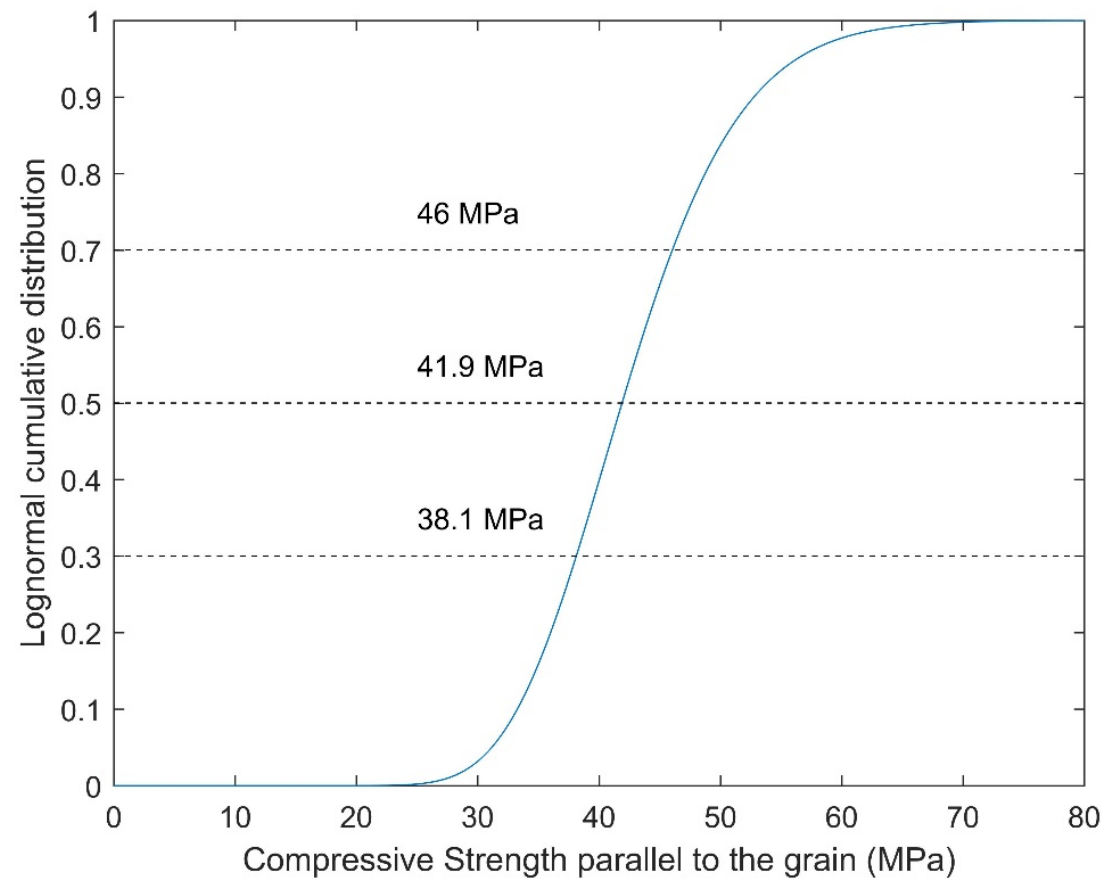

(b)

Fig. 2. Cumulative distribution function (CDF) of: (a) MOE parallel-to-grain $\left(E_{L}\right)$, and (b) compressive strength parallel-to-grain $\left(\sigma_{c u}\right)$ for radiata veneers of plywood. 

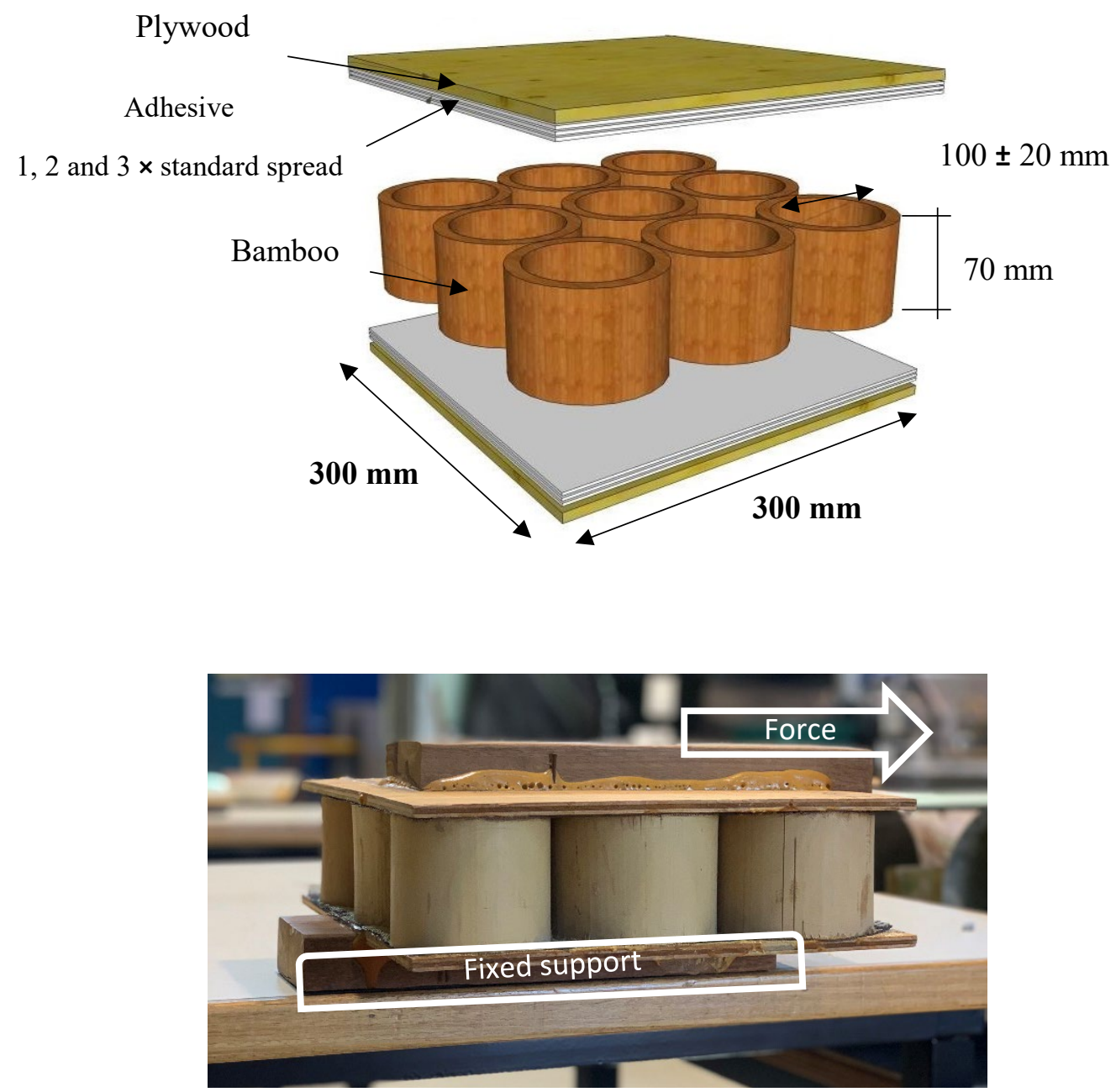

Fig. 3. Shear bond strength tests (BCS-S panels). 

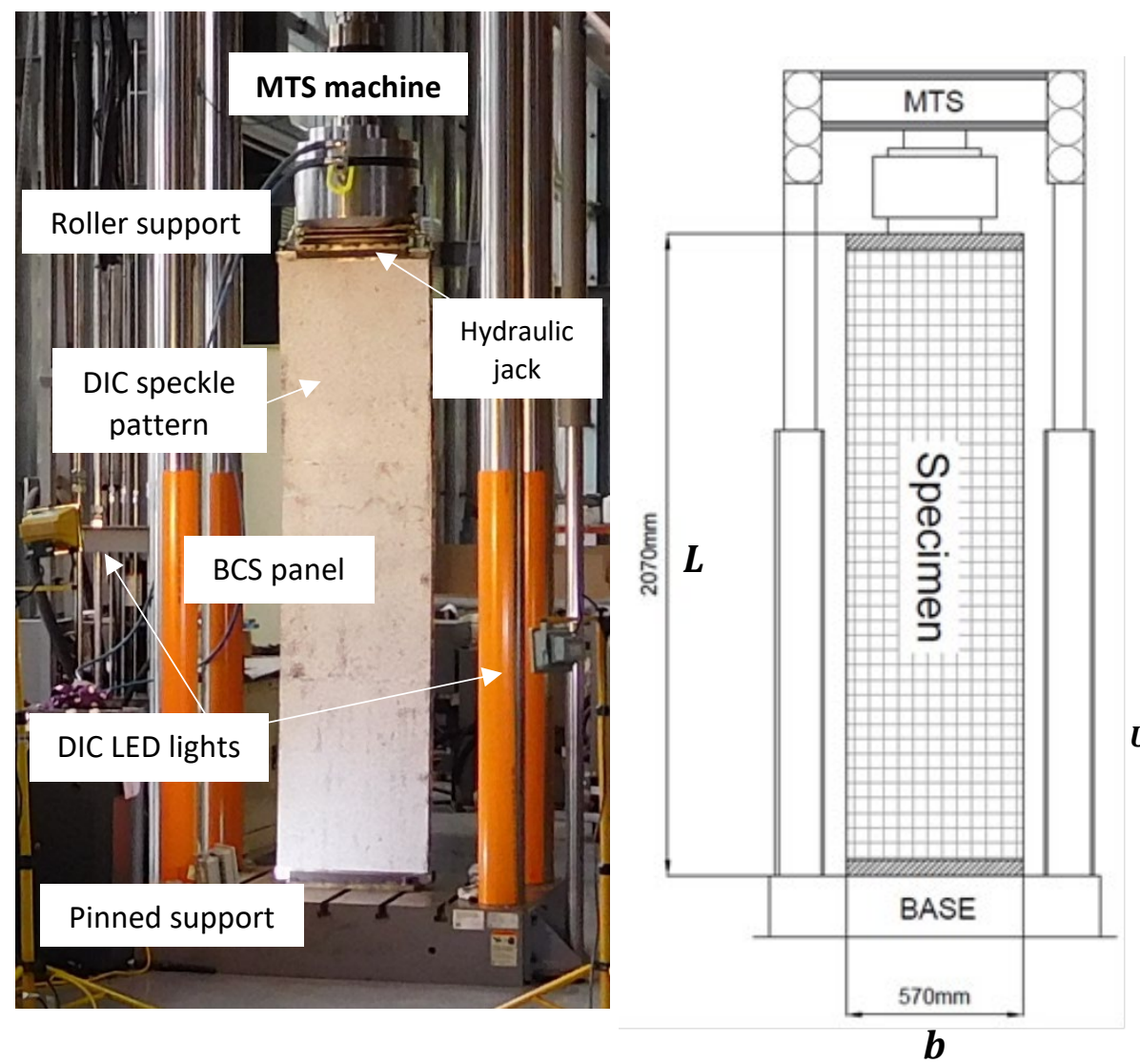

$$
\begin{aligned}
U_{\boldsymbol{y}} & =\boldsymbol{U}_{\boldsymbol{Z}}=\mathbf{0} \\
\boldsymbol{R}_{X}=\boldsymbol{R}_{\boldsymbol{Z}} & =\mathbf{0}
\end{aligned}
$$

Roller support

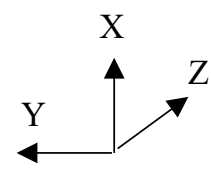

$\boldsymbol{U}_{X}=\boldsymbol{U}_{Y}=\boldsymbol{U}_{Z}=\mathbf{0}$

$\boldsymbol{R}_{X}=\boldsymbol{R}_{Z}=\mathbf{0}$

Pinned support

Fig. 4. Axial compression test setup showing the BCS panel, test machine and the adopted boundary conditions. 


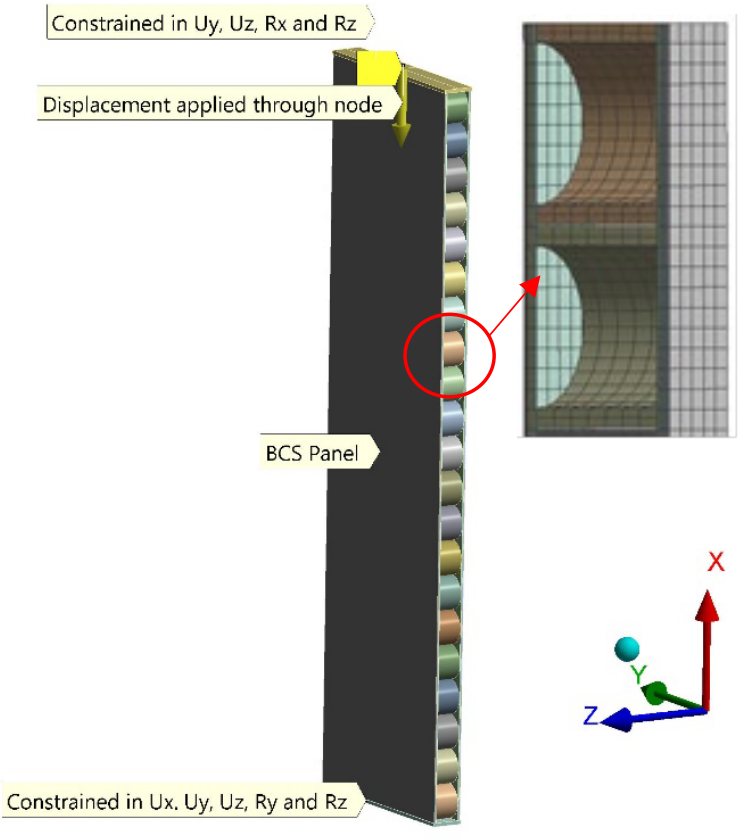

(a)

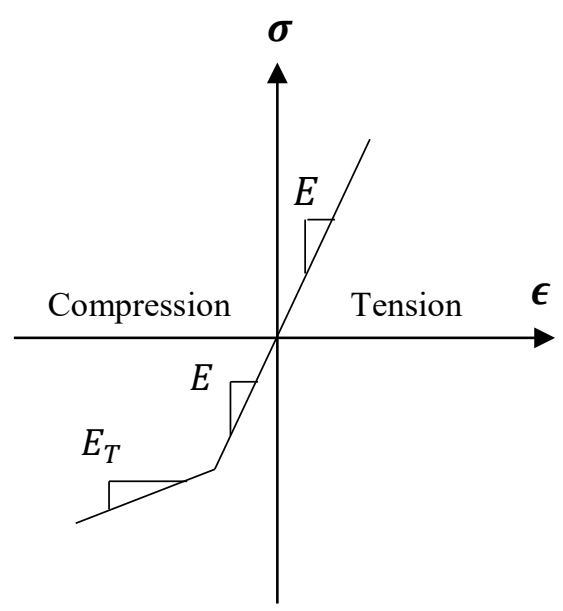

(b)

Fig. 5. (a) The mesh, and (b) the adopted stress-strain relationship model of plywood veneers used in the FEA.

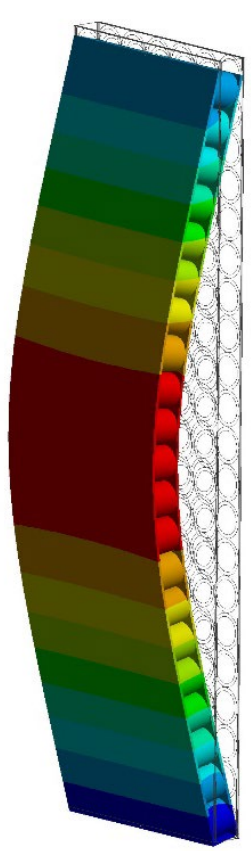

Mode I

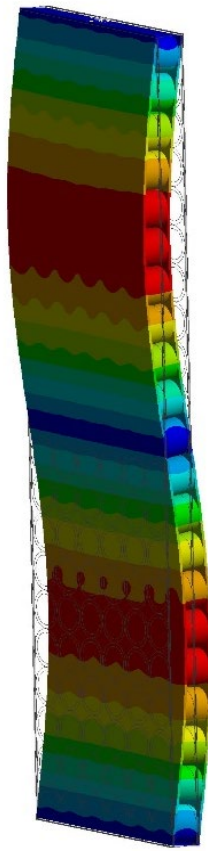

Mode II

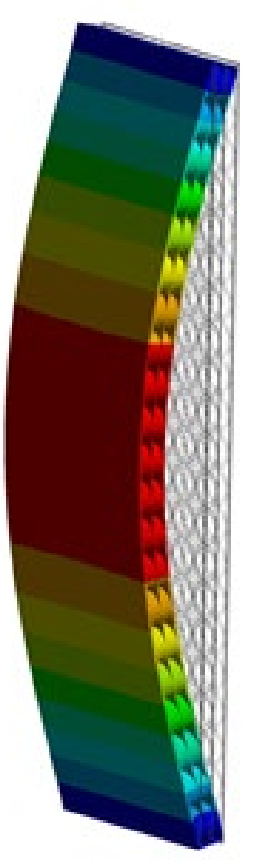

Mode I

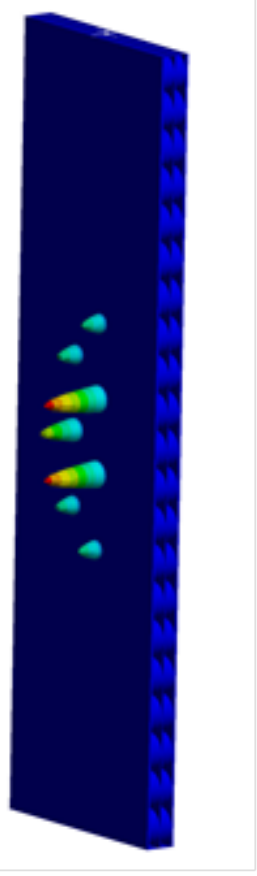

Mode II

(a)

(b)

Fig. 6. FEA results showing buckling mode shapes I and II in (a) the BCS-S panel, and (b) BCS-D panel. 


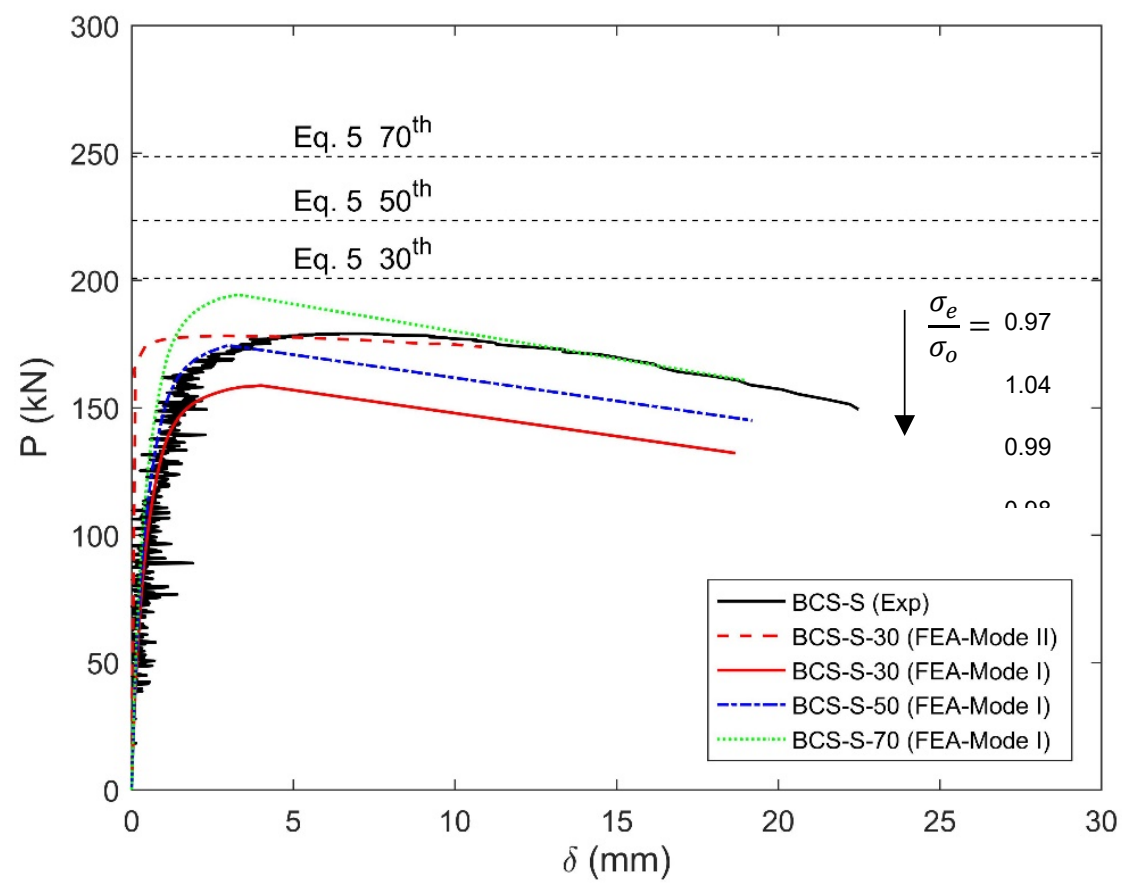

(a) 


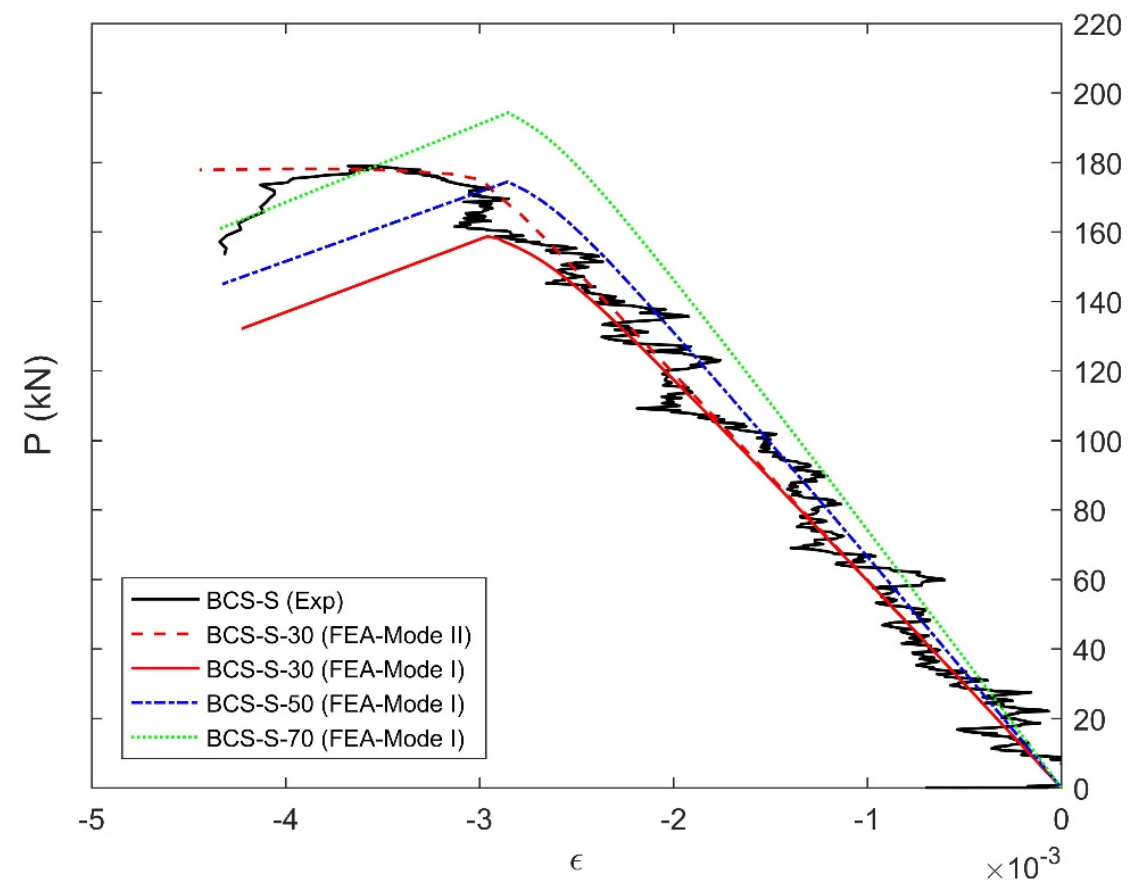

(b)

Fig. 7. Comparison between experimental and FEA results: (a) load vs. mid-lateral displacement, and (b) load vs. longitudinal strain curves in BCS-S panels with various MOE and MOR percentiles $\left(30^{\text {th }}, 50^{\text {th }}\right.$ and $\left.70^{\text {th }}\right)$.

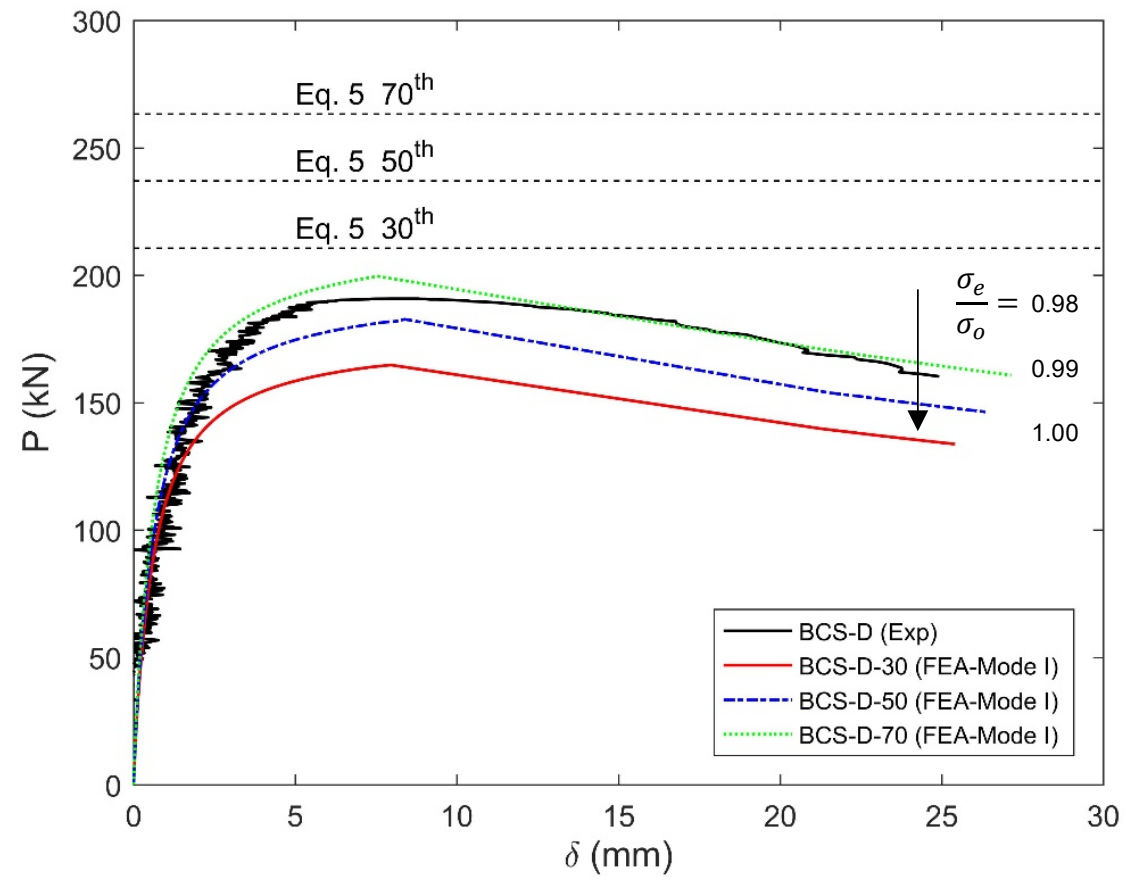


(a)

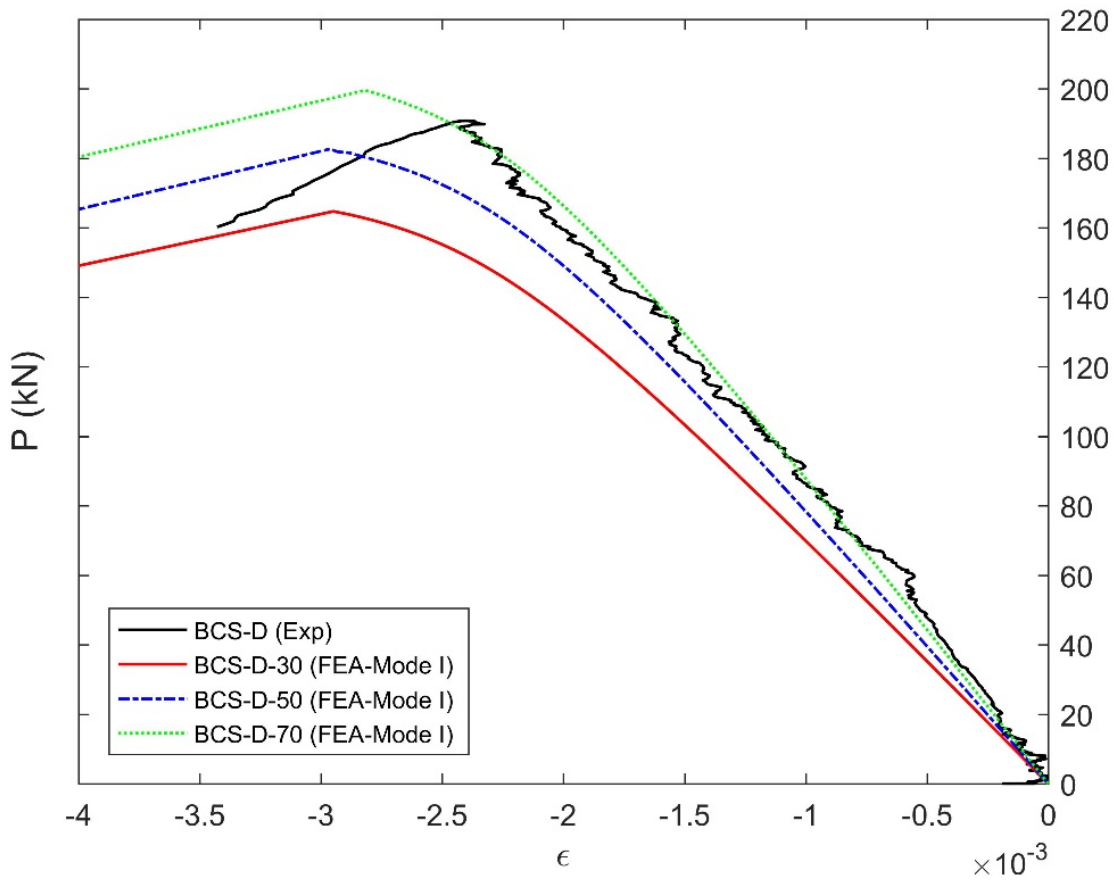

(b)

Fig. 8. Comparison between the experimental and FEA results: (a) load vs. mid-lateral displacement, and (b) load vs. longitudinal strain in BCS-D panels with various MOE and MOR percentiles $\left(30^{\text {th }}, 50^{\text {th }}\right.$ and $\left.70^{\text {th }}\right)$. 

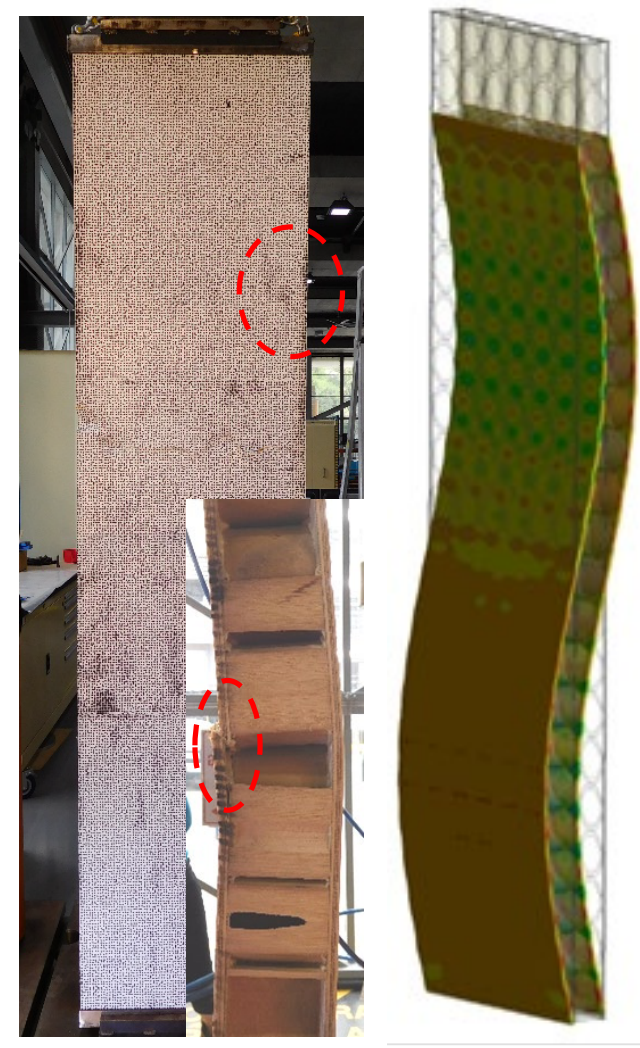

(a)
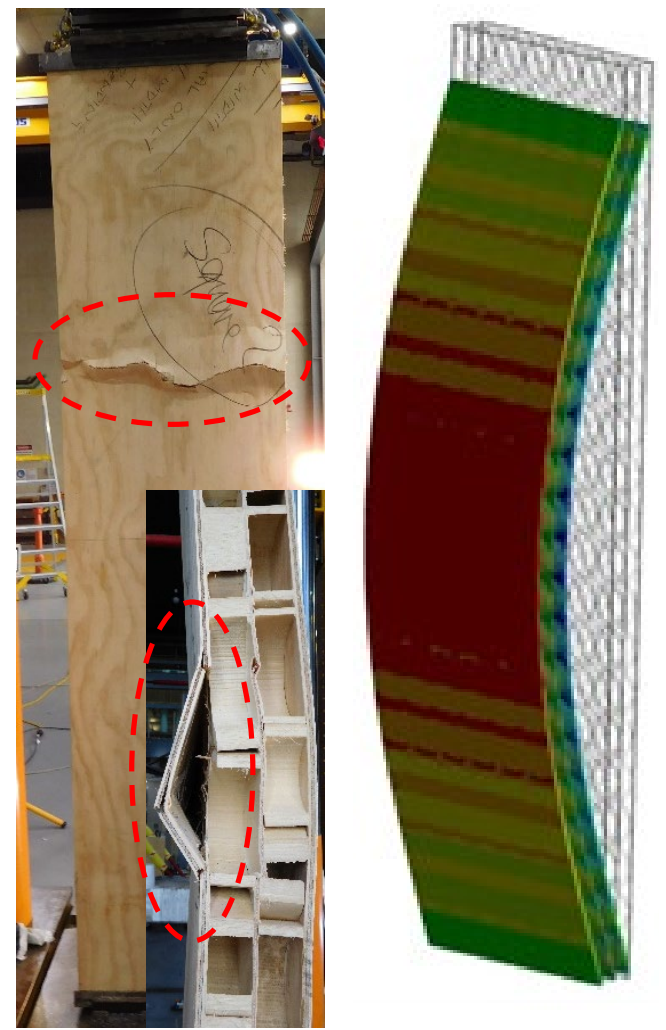

(b)

Fig. 9. Experimental and exaggerated FEA failure modes of the BCS panels subjected to compressive axial load; (a) BCS-S panel with FEA-Mode II-30 ${ }^{\text {th }}$, and (b) BCS-D panel with FEA-Mode I-70 ${ }^{\text {th }}$. FEA results show the longitudinal strain contours. 


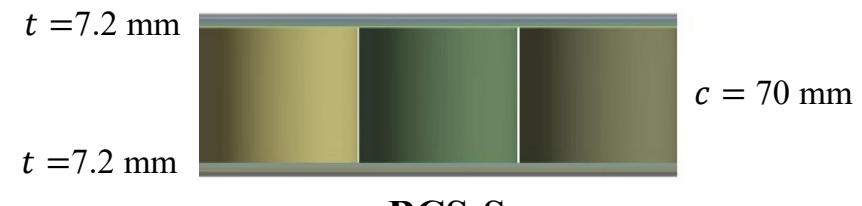

BCS-S

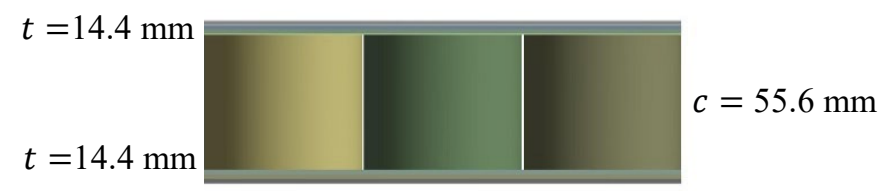

BCS-S1

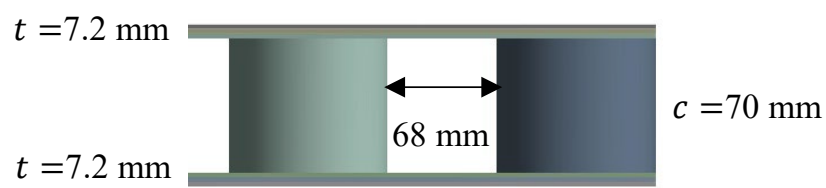

BCS-S2

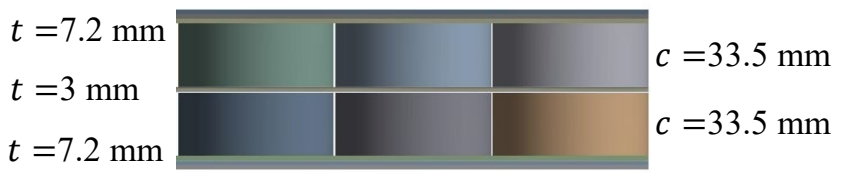

BCS-D

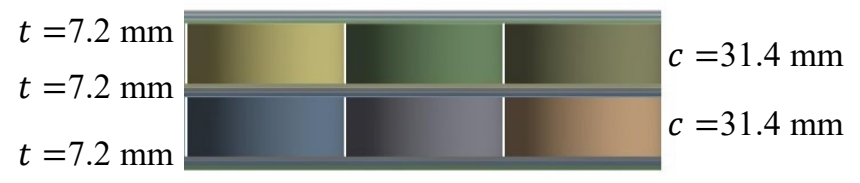

BCS-D1

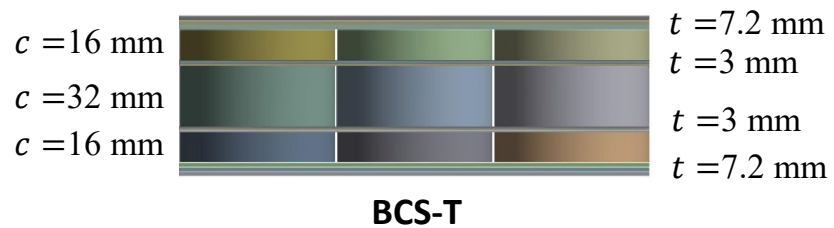

(a) 


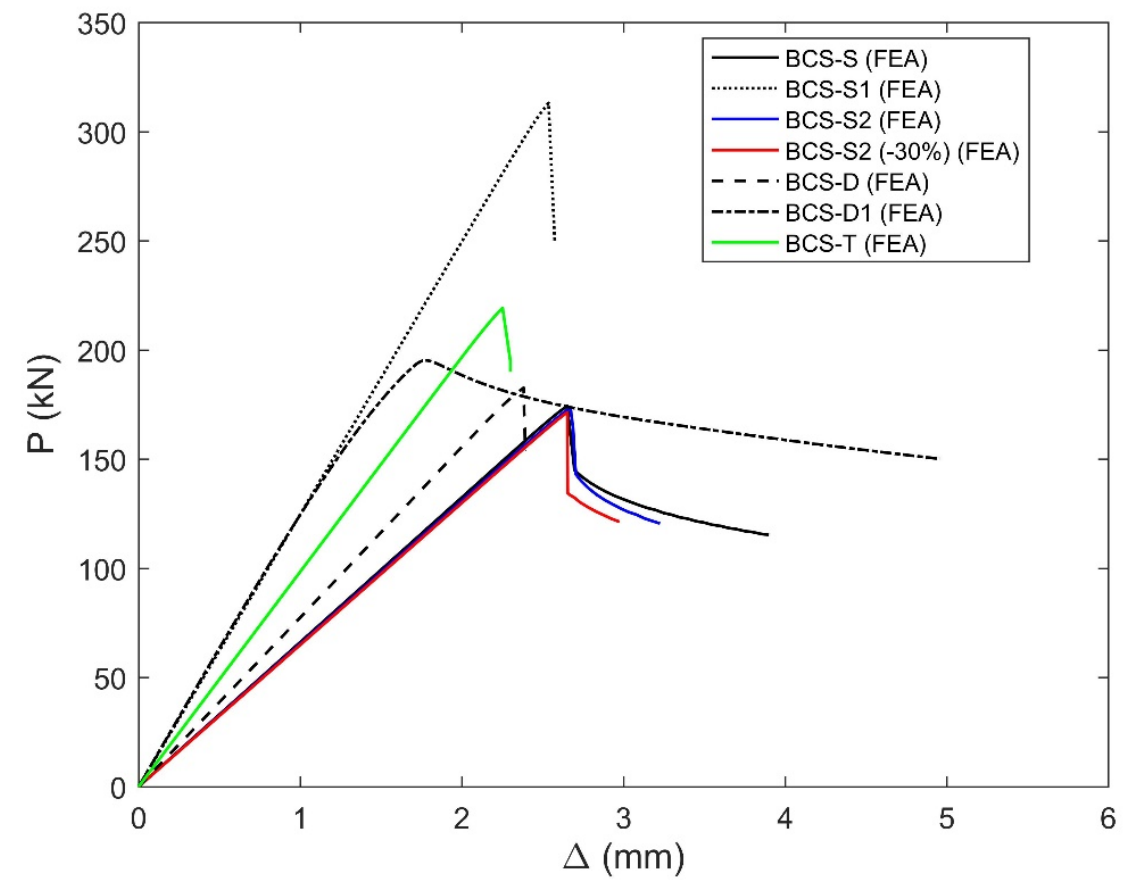

(b)

Fig. 10. Optimised core configuration study showing: (a) assumed core configurations in the BCS panels, and (b) corresponding load vs. axial displacement from the FEA. 
Table 1. Material properties of bamboo and Pine radiata veneers (Fig. 2) used in the BCS panels.

\begin{tabular}{cccccccccc}
\hline Material & $E_{L}(\mathrm{MPa})$ & $E_{T}(\mathrm{MPa})$ & $E_{R}(\mathrm{MPa})$ & $G_{L T}(\mathrm{MPa})$ & $G_{T R}(\mathrm{MPa})$ & $G_{L R}(\mathrm{MPa})$ & $v_{L T}$ & $v_{T R}$ & $v_{L R}$ \\
\hline Moso Bamboo & 10,500 & 1,260 & 1,260 & 630 & 630 & 630 & 0.3 & 0.3 & 0.3 \\
Species Pine (radiata) $-30^{\text {th }}$ & 9,993 & 450 & 740 & 530 & 100 & 550 & 0.444 & 0.387 & 0.392 \\
Species Pine (radiata) $-50^{\text {th }}$ & 11,220 & 505 & 830 & 595 & 112 & 617 & 0.444 & 0.387 & 0.392 \\
Species Pine (radiata) $-70^{\text {th }}$ & 12,590 & 566 & 932 & 667 & 126 & 692 & 0.444 & 0.387 & 0.392 \\
\hline
\end{tabular}

Note: Subscripts $L, T$ and $R$ are associated with the longitudinal, tangential and radial directions, respectively.

Table 2. The material properties of the BCS panel plywood skins calculated from the classical laminate theory [29].

\begin{tabular}{|c|c|c|c|c|c|c|}
\hline Plywood ID & Pine (Radiata) veneer grade & $E_{L}(\mathrm{MPa})$ & $E_{T}(\mathrm{MPa})$ & $G_{L T}(\mathrm{MPa})$ & $v_{L T}$ & Layer's thickness (mm) and lay-up \\
\hline $7-24-3$ [29] & $30^{\text {th }}$ & 6,862 & 3,657 & 530 & 0.03 & $2.4 / 2.4 / 2.4$ \\
\hline $7-24-3$ [29] & $50^{\text {th }}$ & 7,704 & 4,106 & 595 & 0.03 & $2.4 / 2.4 / 2.4$ \\
\hline $7-24-3$ [29] & $70^{\text {th }}$ & 8,645 & 4,608 & 667 & 0.05 & $2.4 / 2.4 / 2.4$ \\
\hline BCS-S (7-24-3)-Tensile test & - & $7,781(\mathrm{CoV}=11 \%)$ & - & - & - & $2.4 / 2.4 / 2.4$ \\
\hline
\end{tabular}


Table 3. The Hill yield constants for Radiata veneers of plywood skins in FE model of BCS panels.

\begin{tabular}{ccccccccc}
\hline Material & $\sigma_{c u}^{\prime \prime}(\mathrm{MPa})$ & $\sigma_{c y}^{\prime \prime}(\mathrm{MPa})$ & $R_{L L}$ & $R_{T T}$ & $R_{R R}$ & $R_{L T}$ & $R_{T R}$ & $R_{L R}$ \\
\hline Species Pine (radiata) $-30^{\text {th }}$ & 38.1 & 28.6 & 1 & 0.18 & 0.19 & 0.67 & 0.48 & 0.67 \\
Species Pine (radiata) $-50^{\text {th }}$ & 41.9 & 31.4 & 1 & 0.17 & 0.18 & 0.60 & 0.44 & 0.6 \\
Species Pine (radiata) $-70^{\text {th }}$ & 46.0 & 34.5 & 1 & 0.15 & 0.16 & 0.55 & 0.40 & 0.55 \\
\hline
\end{tabular}

Table 4. Summary of adhesive shear block tests in BCS panels.

\begin{tabular}{|c|c|c|c|c|}
\hline Specimen & $\begin{array}{l}\text { Spread rate of adhesive } \\
\qquad\left(\mathrm{g} / \mathrm{m}^{2}\right)\end{array}$ & Bamboo wall-thickness area $\left(\mathrm{mm}^{2}\right)$ & Failure load $(\mathrm{kN})$ & Shear bond strength (MPa) \\
\hline BCS 1-1 & & 19,330 & 25.4 & 1.31 \\
\hline BCS 1-2 & & 23,458 & 26.7 & 1.14 \\
\hline BCS 1-3 & 180 & 24,174 & 17.8 & 0.74 \\
\hline BCS 1-4 & & 19,695 & 15.8 & 0.80 \\
\hline $\operatorname{Avg}(\mathrm{COV})$ & & $21,664(11 \%)$ & $21.4(25 \%)$ & $0.99(27 \%)$ \\
\hline BCS 2-1 & & 18,715 & 22.4 & 1.20 \\
\hline BCS 2-2 & 360 & 23,421 & 27.1 & 1.16 \\
\hline BCS 2-3 & & 21,365 & 26.6 & 1.25 \\
\hline BCS 2-4 & & 17,697 & 19.3 & 1.09 \\
\hline
\end{tabular}




\begin{tabular}{|c|c|c|c|c|}
\hline $\operatorname{Avg}(\mathrm{COV})$ & & $20,299(13 \%)$ & $23.8(16 \%)$ & $1.17(5 \%)$ \\
\hline BCS 3-1 & & 24,913 & 27.7 & 1.11 \\
\hline BCS 3-2 & & 20,963 & 25.0 & 1.19 \\
\hline BCS 3-3 & 540 & 26,089 & 31.7 & 1.21 \\
\hline BCS 3-4 & & 20,113 & 25.4 & 1.26 \\
\hline $\operatorname{Avg}(\mathrm{COV})$ & & $23,019(13 \%)$ & $27.4(11 \%)$ & $1.19(5 \%)$ \\
\hline
\end{tabular}

Table 5. Material properties of the CLT laminations.

\begin{tabular}{|c|c|c|c|c|c|c|}
\hline & $\begin{array}{c}\text { MOE } \\
\text { (parallel to span) } \\
(\mathrm{MPa})\end{array}$ & $\begin{array}{c}\text { MOE } \\
\text { (perpendicular to span) } \\
(\mathrm{MPa})\end{array}$ & $\begin{array}{l}\text { Shear Modulus } \\
\text { (parallel to span) } \\
(\mathrm{MPa})\end{array}$ & $\begin{array}{c}\text { Shear Modulus } \\
\text { (perpendicular to span) } \\
(\mathrm{MPa})\end{array}$ & $\begin{array}{l}\text { Compression strength } \\
\mathrm{f}_{\mathrm{c}} \text { (parallel to span) } \\
(\mathrm{MPa})\end{array}$ & $\begin{array}{c}\text { Bending strength } \mathrm{f}_{\mathrm{b}} \\
\text { (parallel to span) } \\
(\mathrm{MPa})\end{array}$ \\
\hline External laminations & 8,000 & 267 & 500 & 50 & 18 & 14 \\
\hline Internal laminations & 6,000 & 200 & 375 & 37.5 & 15 & 10 \\
\hline
\end{tabular}


Table 6. Combined loading results BCS-S, BCS-D and BCS-S1 panels with length of $2.1 \mathrm{~m}$ and using $50^{\text {th }}$ percentiles.

\begin{tabular}{|c|c|c|c|c|c|c|c|c|c|c|c|c|c|c|}
\hline & \multicolumn{2}{|c|}{ Nominal loading } & \multicolumn{4}{|c|}{ BCS-S } & \multicolumn{4}{|c|}{ BCS-D } & \multicolumn{4}{|c|}{ BCS-S1 } \\
\hline & $P$ & $w(\mathrm{kPa})$ & $P_{r}(\mathrm{kN})$ & $\begin{array}{c}w_{u l t} \\
(\mathrm{kPa})\end{array}$ & $P / P_{r}$ & $\begin{array}{c}\text { Failure } \\
\text { mode }\end{array}$ & $P_{r}(\mathrm{kN})$ & $\mathrm{w}_{\text {ult }}(\mathrm{kPa})$ & $P / P_{r}$ & $\begin{array}{c}\text { Failure } \\
\text { mode }\end{array}$ & $P_{r}(\mathrm{kN})$ & $\begin{array}{c}w_{u l t} \\
(\mathrm{kPa})\end{array}$ & $P / P_{r}$ & $\begin{array}{c}\text { Failure } \\
\text { mode }\end{array}$ \\
\hline$p \rightarrow w$ & $30 \% P_{r}$ & - & & 8.44 & & interface & & 10.50 & & interface & & 15.5 & & interface \\
\hline load path & $\begin{array}{l}50 \% P_{r} \\
70 \% P_{r}\end{array}$ & $\begin{array}{l}- \\
-\end{array}$ & 174.4 & $\begin{array}{l}4.65 \\
2.01\end{array}$ & - & $\begin{array}{l}\text { interface } \\
\text { interface }\end{array}$ & 195.7 & $\begin{array}{l}5.96 \\
2.93\end{array}$ & - & $\begin{array}{l}\text { interface } \\
\text { interface }\end{array}$ & 315.3 & $\begin{array}{l}6.18 \\
2.85\end{array}$ & - & $\begin{array}{l}\text { interface } \\
\text { interface }\end{array}$ \\
\hline $\begin{array}{c}w \rightarrow p \\
\text { load path }\end{array}$ & - & $2 \mathrm{kPa}$ & - & - & 0.81 & buckling & - & - & 0.74 & buckling & - & - & 0.77 & buckling \\
\hline
\end{tabular}

